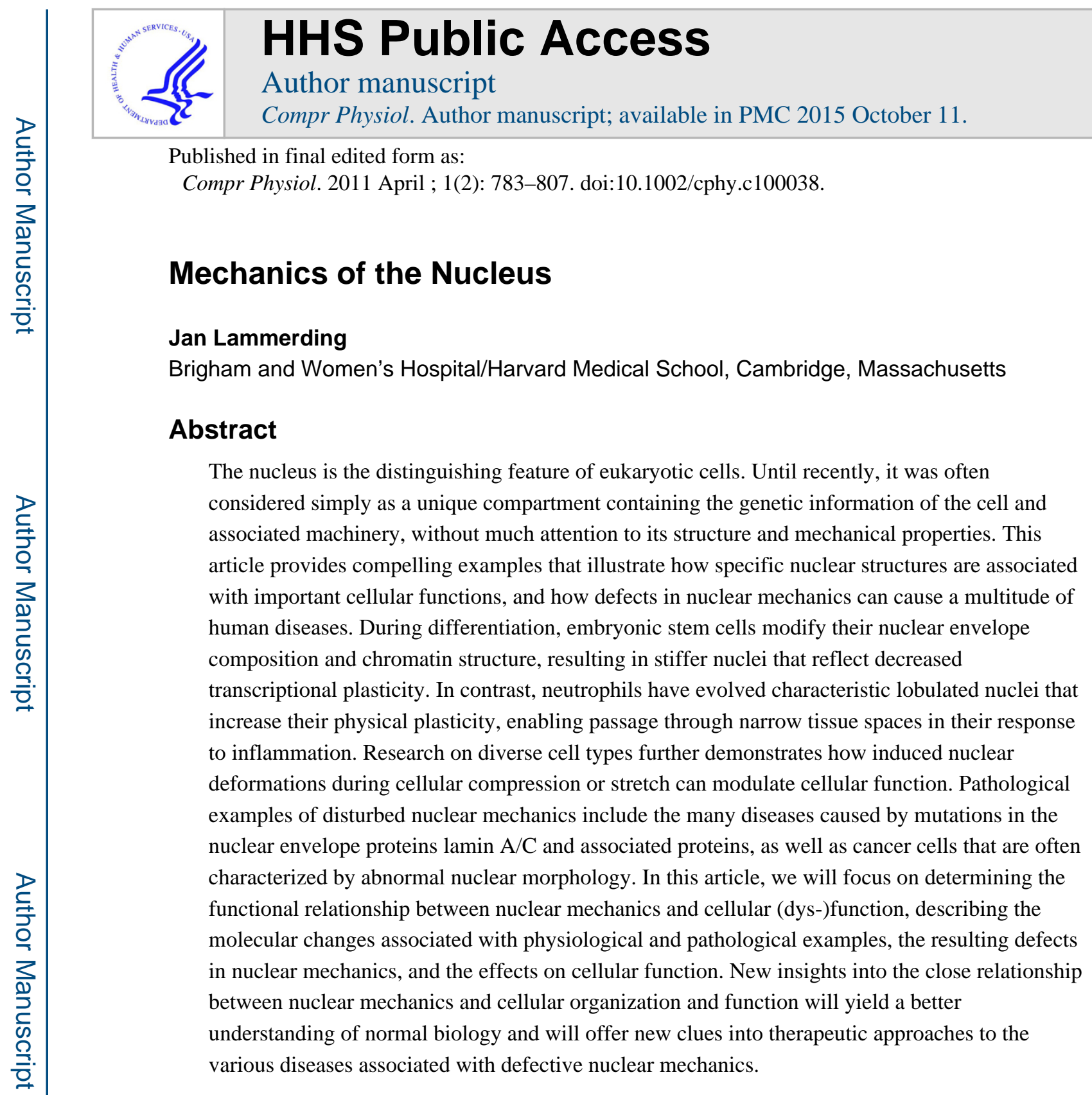

\title{
Keywords
}

Diseases; mechanotransduction; muscle; differentiation; stem cells

The nucleus is the largest organelle in most cells. In addition to housing the genetic information and serving as the site of DNA and RNA synthesis, transcription, and processing, it plays an important role in coordinating the intricate cellular architecture (112). In differentiated cells, the nucleus is approximately 5 to 10 times stiffer than the surrounding cytoskeleton; based on its size and stiffness, the mechanical properties of the nucleus will often dominate the overall cellular behavior during physiological deformations, for example during cell migration or perfusion through narrow capillaries. The mechanical properties of

\footnotetext{
Correspondence: Jan Lammerding, jlammerding @ rics.bwh.harvard.edu.

* Present address: Jan Lammerding, Weill Institute for Cell and Molecular Biology, Meinig School of Biomedical Engineering,

Cornell University, Weill Hall, Room 235, Ithaca, NY 14853, USA, Jan.lammerding@cornell.edu
} 
the nucleus are defined by its unique structure and architecture, particularly the nuclear envelope, consisting of nuclear membranes and the nuclear lamina, and the nuclear interior, mostly comprised of chromatin and the nucleoskeleton. Consequently, changes in nuclear stiffness often reflect structural changes in the nuclear envelope, the chromatin organization, or both. For example, stem cells increase the expression of specific nuclear envelope proteins during differentiation and modify their chromatin structure, resulting in a 5-fold increase of nuclear stiffness (146). On the other hand, changes in the nuclear envelope composition during granulopoiesis are responsible for the characteristic lobulated nuclei in neutrophils that are ideally suited to pass through narrow spaces during transendothelial migration and tissue infiltration (140). Nuclear structure and mechanics are also altered in a variety of human diseases, with much of the research focused on determining the functional relationship between altered nuclear morphology and cellular dysfunction. For example, mutations in the $L M N A$ gene encoding the nuclear intermediate filament proteins lamin A and $\mathrm{C}$ cause at least 10 different human diseases, including muscular dystrophies, cardiomyopathies, lipodystrophies and progerioid phenotypes (202). In at least some of these diseases, defects in nuclear mechanics are thought to contribute to the disease progression (107). Other disorders associated with abnormal nuclear architecture include Pelger-Huet anomaly, caused by mutations in the lamin B receptor (LBR) protein, and cancer, which is often recognized by pathologists based on characteristic defects in nuclear morphology. The plethora of human diseases and the multitude of tissues affected in these diseases suggests that nuclear mechanics are not only relevant for direct structural functions such as protecting the genomic information, particularly in mechanically stressed tissues such as muscle, but could also contribute to other cellular functions such as cell signaling and migration. Abnormal activation of mechanosensitive genes has been reported in lamin A/C-deficient-fibroblasts (107) and in mice with reduced levels of lamin A/C $(35,136)$, suggesting a role of nuclear mechanics in mechanotransduction signaling.

In the following, we present a detailed overview of nuclear structure and organization under normal and pathological conditions, describe the relevance of nuclear deformations in vivo and in vitro, including a brief overview of experimental techniques to probe nuclear mechanics, and finally discuss the role of nuclear mechanics during stem cell differentiation and in various diseases associated with changes in nuclear structure and mechanics.

\section{Nuclear structure and organization}

The nucleus is the distinguishing feature of eukaryotic cells, separating the genome and transcriptional machinery from the cytoplasm. Most mammalian cells have a single ovoid or spherically shaped nucleus with a diameter of 5 to $20 \mu \mathrm{m}$, making it the largest cellular organelle. Cardiac myocytes and skeletal muscle cells are often multi-nucleated, whereas mature red blood cells no longer contain a nucleus. The nuclear shape and size within a given cell depends on the cell type and also varies with the particular morphology of the cell (99). For example, the nucleus of a fibroblast grown under standard (i.e., 2-dimensional) cell culture conditions resembles a flat disk with a diameter of 10 to $20 \mu \mathrm{m}$ and a height of only 3 to $6 \mu \mathrm{m}$ (Fig. 1). In contrast, cells imaged in vivo or cultured in 3-dimensional collagen gels typically have spherical (Fig. 2) or ovoid nuclei with a diameter of 6 to $10 \mu \mathrm{m}$. Irrespective of the exact shape and size of the nucleus, the nuclear structure can be generally 
divided into two distinct compartments: (i) The nuclear envelope, consisting of the inner and outer nuclear membrane, the nuclear pores, and the nuclear lamina, and (ii) the nuclear interior, comprised of chromatin, the nucleoskeleton, and other intranuclear structures such as the nucleolus and PML bodies (Fig. 2).

\section{The nuclear envelope}

Nuclear membranes and membrane proteins-The nuclear envelope is comprised of two lipid bilayers, the inner and the outer nuclear membranes, which enclose the approximately 30 to $50 \mathrm{~nm}$ wide perinuclear space. The outer nuclear membrane is continuous with the endoplasmic reticulum (ER) and joins the inner nuclear membrane at the nuclear pores. As a result, nuclear membrane proteins can diffuse laterally between the inner nuclear membrane, the outer nuclear membrane, and the ER, with some restrictions imposed on the size of the inner nuclear membrane proteins by the necessity to pass by the nuclear pores. Proteins specific to the inner nuclear membrane are thought to be retained there through interaction with other inner nuclear membrane proteins or interactions with the underlying nuclear lamina or chromatin (diffusion-retention model). Consequently, disruption of these interactions, for example through loss of nuclear lamina proteins or dominant negative mutants, can cause mislocalization of these proteins away from the inner nuclear membrane to the ER. Based on a recent proteomic analysis, the inner and outer nuclear membranes are home to at least 50 to 100 specific membrane proteins (165), with many of the proteins still incompletely characterized. Examples of inner nuclear membrane proteins include emerin, lamin B receptor (LBR), SUN1 and SUN2, and several isoforms of the lamina-associated proteins (LAP), with the exception of LAP2a, which is nucleoplasmic. Outer nuclear membrane proteins include the large nesprin isoforms, which play a prominent role in nuclear cytoskeletal coupling (see below).

Among the inner nuclear membrane proteins, emerin has received special attention, as mutations in the EMD gene cause X-linked Emery-Dreifuss muscular dystrophy (134). Emerin has been shown to promote actin polymerization (85) and could, together with aIIspectrin (206) and 4.1R (102), form stable networks at the nuclear envelope, similar to the cortical network found in erythrocytes $(84,85)$.Emerin can also directly interact with nuclear myosin I (87), which could be involved in intranuclear movement. Fibroblasts from emerin-deficient mice have abnormally shaped nuclei, which undergo dynamic fluctuations in nuclear shape (106), and have altered nuclear mechanics when probed in micropipette aspiration experiments (161); however, nuclear deformations were normal when emerindeficient cells were subjected to substrate strain (106), suggesting that loss of emerin may cause localized defects in nuclear envelope mechanics without affecting overall nuclear stiffness. The effect of emerin is not limited to the nuclear interior; emerin has also been proposed to participate in linking microtubules to the nuclear envelope (163), and lack of emerin results in the detachment of centrosomes from the nucleus and the prevention of centrosome polarization in living cells in response to fluid shear stress (69).

In addition to its structural role, emerin binds to a number of important nuclear factors such as the transcriptional repressor Btf, the transcription factors germ-cell-less (gcl) and Lmo7, the DNA-binding protein barrier-to-autointegration factor (BAF), and the splicing associated 
factor YT521-B (7, 73, 86, 162, 197, 199), suggesting an important role of emerin in gene regulation.

The nuclear lamina-Underlying the inner nuclear membrane is the nuclear lamina, a dense protein network mainly comprised of lamins, type $\mathrm{V}$ intermediate filaments specific to the nucleus. Lamins act as major "guardians" to the structural organization and function of the nucleus. Similar to other intermediate filaments, lamins can assemble into approximately $10 \mathrm{~nm}$ thick filaments in vitro; similar sized fibers have been imaged in vivo by electonmicroscopy in Xenopus oocytes $(1,61)$. However, no such structures have been observed to date in somatic cells, and the precise assembly and higher order organization of lamins within the nuclear lamina remain incompletely understood. In addition to their structural role, lamins are directly implicated in DNA replication, DNA repair, RNA synthesis, and chromatin folding $(103,172,180)$. Consequently, lamins play a dynamic role in several cell processes, including cell division, differentiation, migration, aging, and apoptosis(45).

Somatic mammalian cells contain two types of lamins, A-type (mainly lamins A and C) and B-type lamins (lamin B1 and B2), each having tissue-specific expression patterns. At least one B-type lamin is constitutively expressed in all cells, while expression of A-type lamins is developmentally regulated and generally restricted to differentiated cells. Based on microscopic observations of fluorescently-tagged lamins and immunofluorescence labeling, A- and B- type lamins form distinct, albeit overlapping, stable networks (170).

A-type lamins are encoded by a single gene, $L M N A$, and result from alternative splicing. Atype lamins are developmentally regulated, beginning midway through embryonic development (177), and are abundantly expressed in most differentiated cells, but not in embryonic stem cells (166). Lamins A and C provide structural support to the nuclear envelope, are critical for correct spacing of nuclear pore complexes, and interact with chromatin and a variety of inner nuclear membrane proteins such as emerin, SUN1, and some shorter nesprin isoforms (208). While lamins were initially identified as structural proteins, it has now become apparent that they also play important roles in cell signaling. Lamins $\mathrm{A}$ and $\mathrm{C}$ can directly interact with several transcription factors such as the adipocyte differentiating factor sterol response element binding protein 1 (SREBP1) (119), MOK2 (49), c-Fos (62), and retinoblastoma ( $\mathrm{pRb}$ ) protein (142), modulating their nuclear activity by, for example, sequestering certain proteins at the nuclear envelope or protecting them from degradation. Recently, A-type lamins have gathered increased attention in the biological and clinical sciences as more than 300 different disease-causing mutations have been identified in the LMNA gene. These diseases, collectively referred to as laminopathies, include Emery-Dreifuss muscular dystrophy, dilated Cardiomyopathy with conduction defects, Dunnigan-type familial partial lipodystrophy, Charcot-Marie-Tooth disorder (Type II), and Hutchinson-Gilford progeria syndrome (reviewed in (202)). Mice deficient for lamin A/C $\left(\right.$ Lmna $\left.^{-/-}\right)$appear normal at birth but subsequently develop severe muscular dystrophy and dilated cardiomyopathy and die between 4 to 8 weeks of age. Cells derived from these animals have significantly softer and more fragile nuclei and impaired mechanotransduction signaling, thereby providing a potential mechanism for the muscle-specific phenotypes of many laminopathies (107). Interestingly, experiments on fibroblasts derived from mice lacking lamins $\mathrm{A}$ and/or $\mathrm{C}$, or lamin $\mathrm{B} 1$ indicate that lamins $\mathrm{A}$ and $\mathrm{C}$ are the main 
contributors to nuclear stiffness (105). Importantly, loss of lamins A/C results in mislocalization of emerin to the ER (179) and increases the mobility of SUN proteins on the inner nuclear membrane (141), thereby affecting the function of these proteins. Furthermore, loss of lamin $\mathrm{A} / \mathrm{C}$ has consequences beyond the nucleus itself. Lamin $\mathrm{A} / \mathrm{C}-\mathrm{deficient}$ cells have abnormal cytoskeletal organization and decreased cytoskeletal stiffness, resulting in disturbed nuclear orientation and migration $(89,107,112)$.

Lamin B1 and B2, the major B-type lamin isoforms, are encoded by two separate genes, $L M N B 1$ and $L M N B 2$, respectively. In contrast to A-type lamins, B-type lamins are expressed in all cells, although the relative expression between lamins B1 and B2 varies between tissues. The only known diseases associated with B-type lamins are autosomal dominant leukodystrophy caused by duplication of the $L M N B 1$ gene (143) and acquired partial lipodystrophy linked to mutations in the $L M N B 2$ gene (77). The absence of known human mutations, along with the findings that lamin B1 and lamin B2-deficient mice die at birth (190)(Coffinier, in press HMG2010) and that knockdown of B-type lamins is lethal in cultured cells (74), suggest that B-type lamins are critical for survival. While B-type lamins contribute little to the elasticity of the nucleus (105), they are important in anchoring the nucleus to the cytoskeleton. Nuclei in cells lacking functional lamin B1 undergo spontaneous and sustained nuclear rotation (95), and mice lacking lamin B2 have severe brain development defects do to impaired neuronal migration and nuclear movement (29).

\section{The nuclear interior}

Chromatin and chromosome territories-Most of the nuclear interior is occupied by densely packed chromatin, i.e., DNA wrapped around histones and other chromosomal proteins to form nucleosomes and higher order structures such as the typical $30 \mathrm{~nm}$ chromatin fibers. Within the nucleus, chromatin can be found in two distinct configurations: Heterochromatin is condensed, often transcriptionally inactive, and often consists of genepoor regions. Heterochromatin is mostly found at the nuclear periphery, and targeting genes to the nuclear periphery can be sufficient to reduce their expression (184). Euchromatin has a less compact (extended) configuration, promoting access to transcription factors and DNA binding proteins, and is typically comprised of transcriptionally active genes. Euchromatin is found in the nuclear interior and near nuclear pores. Recent experiments based on fluorescence in-situ hybridization (FISH) against various chromosomes revealed that during interphase, chromatin is organized into discrete chromosome territories with only limited overlap, and that the position of these chromosome territories can, at least in part, be passed on to daughter cells (123). The large scale organization of chromatin has been hypothesized as a fractal, knot-free globule that provides maximally dense packing while enabling easy folding and unfolding of specific genomic loci (116).

Intranuclear structures - the nucleoskeleton-The existence of a stable nucleoskeleton comparable to the cytoskeleton has been debated for several decades. While the organization of chromatin into discrete chromosome territories does not require a stable nucleoskeleton (116), stable intranuclear structures could serve as scaffolds in transcriptional regulation and DNA synthesis and transcription. To date, a number of structural proteins have been identified to exist in the nuclear interior, including actin, aII- 
spectrin, myosin, lamins and even the giant molecule titin $(83,206,207)$. The presence of actin in the nucleus is now widely accepted $(8,58,151)$; in the nucleus actin is predominantly in the G-actin state, but can form at least two presumably short oligomers that are not detected by phalloidin $(96,150,152,168)$. In addition to a possible role as a "nuclear cortex" at the nuclear periphery, recent data suggest that nuclear actin maybe be involved in transcription(153), and electron microscopy of Xenopus oocyte nuclei shows actin oligomers interacting with nuclear pores and Cajal bodies at the nuclear periphery(101). Myosin, recently identified in the nucleus, (83) might be implicated in movement of DNA within the nucleus.

It is important to recognize that lamins, particularly A-type lamins, are not restricted to the nuclear lamina, but also form stable intranuclear structures as evidenced by the long fluorescence recovery time during photobleaching experiments (129). These intranuclear lamins, along with other nucleoskeletal structures, could be implicated in chromatin organization and transcription. Interestingly, cells derived from Emery-Dreifuss muscular dystrophy patients and from lamin $\mathrm{A} / \mathrm{C}$-deficient mice have severe changes in chromatin organization that could affect gene regulation $(55,179)$. Furthermore, lamin A/C speckles have been proposed to mediate spatial organization of splicing factor compartments and RNA polymerase II transcription (103), and disrupting the normal organization of nuclear lamins by expression of a dominant-negative lamin mutant inhibits RNA polymerase IIdependent transcription in mammalian cells and in active embryonic nuclei from Xenopus laevis (172).

\section{Nuclear cytoskeletal coupling}

The first direct evidence that externally applied forces could be transmitted from the cell surface to the nucleus was provided by Ingber and colleagues (120). They coated the tip of micropipette with extracellular matrix protein fibronectin and placed the tip on top of the cell apical surface (or alternatively within the cytoskeleton). After allowing the focal adhesion to form around the pipette tip, the pipette was moved away from the cell surface laterally for specified distances $(10-20 \mu \mathrm{m})$ while simultaneously measuring the movement of the nucleus and nuclear structures such as the nucleolus. They found that extracellular or cytoskeletal strain application with the microneedle was transmitted through the cytoskeleton to the nucleus, resulting in significant induced nuclear deformations and occasional evagination of the nuclear envelope towards the force application site. Despite this direct evidence for nuclear-cytoskeletal coupling, the molecular mechanism by which the nucleus is connected to the cytoskeleton has puzzled researchers for many years, as it was unclear how forces could be transmitted across the 30 to 50-nm wide perinuclear space. Recent work in C. elegans, Drosophila melanogaster, and mammalian cells led to the discovery of two new families of nuclear envelope proteins that are ideally suited to transmit forces from the cytoskeleton across the nuclear envelope to the nuclear interior $(33,70,115$, $132,144,145,148,193,203,211)$. These findings have shaped the current model of nuclear-cytoskeletal coupling (Fig. 3), in which large nesprin isoforms located on the outer nuclear membrane can bind to cytoskeletal F-actin or, via plectin, intermediate filaments. Additional interactions of nesprins with microtubules and the centrosome, via dynein/ dynactin and kinesin complexes, have also been reported (213). At the nuclear envelope, 
nesprins interact across the perinuclear space with SUN proteins, which are located at the inner nuclear membrane. There, SUN proteins can bind to lamins, inner-membrane-localized nesprin isoforms, nuclear pore complex proteins, chromatin, and other, yet-to be identified nuclear envelope proteins, thereby creating a physical link between the cytoskeleton and the nucleus $(48,71,167,204)$. Because of this function, the nesprin/SUN protein complex is referred to as the LINC complex (Linker of Nucleoskeleton and Cytoskeleton) (33). The molecular components of the LINC complex are described in more detail below.

Nesprins-Nesprins are a novel family of spectrin-repeat proteins anchored at the nuclear envelope. To date, four nesprin genes (nesprin-1, -2, and -3, and -4) have been identified (21). As a result of multiple initiation and splicing sites, many of the nesprins are expressed in multiple isoforms that vary in length, domain composition, and expression patterns. For nesprin-1 and nesprin-2, the exact localization and function of specific isoforms is not always clear, as most isoforms remain uncharacterized, and many antibodies recognize more than one isoform. However, there is convincing evidence that the largest isoforms (Nesprin-1 Giant and Nesprin-2 Giant), which are more than $800 \mathrm{kD}$ in size and are predicted to be up to $0.4 \mu \mathrm{m}$ long, are located in the outer nuclear membrane and can bind to the actin cytoskeleton (211). The giant nesprin isoforms consist of a central rod domain with a variable number of spectrin repeats that is flanked by a cytoplasmic, $\mathrm{N}$-terminal actin binding domain and a C-terminal KASH (Klarsicht/ANC-1/Syne-1 homology) domain (211). The highly conserved KASH domain consists of a transmembrane domain and a luminal SUN-binding motif. Interaction of the highly conserved KASH domain with the Cterminal SUN-protein domain is required for localization of all nesprins to the nuclear envelope $(33,70,145)$

Nesprin-1 (also known as Syne-1, Myne-1, or Enaptin) isoforms can directly bind to lamin $\mathrm{A} / \mathrm{C}$ and emerin at the nuclear envelope; the largest isoform can also interact with F-actin in the cytoplasm through its N-terminal actin binding domain (128, 144). Nesprin-1 might also interact with the kinesin II subunit KIF3B, suggesting a potential link between the nuclear envelope and the microtubule network (52). In addition to these cytoskeletal proteins, nesprin-1 also binds to the neuromuscular junction specific kinase MusK and the scaffold protein muscle A Kinase Anchoring Protein (mAKAP) $(4,148)$. Another reason that nesprins are so relevant for the muscular laminopathies is the fact that heart and skeletal muscle are among the tissues with the highest expression levels of nesprin-1 $(4,144)$, and some isoforms (e.g. nesprin-1a $)$ are only found in skeletal, cardiac, and smooth muscle (4, 212). The importance of nesprins for muscular function is further illustrated by the discovery that nesprin-1 is required for nuclear positioning at neuromuscular junctions (4, 64, 209). Thus, tissue-specific effects caused by mutations in the ubiquitously expressed lamin A/C could arise from its interaction with tissue-specific nesprin isoforms.

Similar to nesprin-1, the larger nesprin-2 isoforms (also known as Syne-2, Myne-2, or Nuance) localize to the outer nuclear membrane and contain an N-terminal actin binding domain $(211,214)$, although Western analysis suggests that additional, shorter isoforms may exist that also contain the actin-binding domain (211). The smaller nesprin-2 isoforms bind directly to lamin A and emerin at the inner nuclear envelope. Importantly, lamin A/C is necessary for the correct localization of nesprin- 2 to the nuclear envelope $(115,211)$, either 
through direct interaction or by affecting SUN2 localization. Depletion of SUN1 and SUN2 or expression of the luminal SUN1 domain (that acts as a dominant-negative mutant) result in mislocalization of nesprin-2 Giant away from the nuclear membrane and expansion of the perinuclear space to $100 \mathrm{~nm}$ or more (33). Similar to nesprin-1, nesprin-2 also expresses muscle-specific isoforms (e.g. nesprin-2 $\mathrm{a}_{1}$ ); and during differentiation of $\mathrm{C} 2 \mathrm{C} 12$ myoblasts, nesprin-2 relocalizes from the nuclear envelope to the sarcomeres (211). In adult skeletal muscle, nesprin-2 is present at the Z-line and the sarcoplasmic reticulum (211).

Nesprin-3 was discovered as a ubiquitously expressed third member of the mammalian nesprin family that is located in the outer nuclear membrane (196). Nesprin-3 lacks an actinbinding domain but contains an $\mathrm{N}$-terminal plakin-binding domain that can interact with plectin (196). Plectins are important crosslinkers for actin filaments, microtubules, and intermediate filaments and can also bind to integrin $\beta 4$ subunits, thus establishing a direct connection between the nucleus and the extracellular matrix $(194,196)$.

Most recently, nesprin-4 was identified as an outer nuclear envelope protein in secretory epithelial cells based on sequence homology with the nesprin-2 KASH domain (158). Nesprin-4 binds to kinesin-1; expression of nesprin-4 is sufficient to cause dramatic relocalization of the centrosome and Golgi complex relative to the nucleus, implicating this nesprin isoform in cell polarization in secretory cells.

Importantly, mutations in nesprins- 1 and -2 have been recently mapped to cause EmeryDreifuss muscular dystrophy (210), suggesting that disruption of nuclear cytoskeletal coupling could be sufficient to cause neuromuscular defects. Supporting this notion, two independent mouse models demonstrate that disruption of nesprin-1 function causes an Emery-Dreifuss muscular dystrophy-like phenotype and defects in nuclear positioning at neuromuscular junctions $(156,209)$. Similarly, mutations of the nesprin ortholog ANC-1 lead to abnormal positioning of nuclei and mitochondria in C. elegans (174), and the Drosophila ortholog MSP-300 is required for embryonic muscle morphogenesis and formation of embryonic muscle attachments (157).

SUN proteins-SUN proteins are inner nuclear membrane proteins oriented with their $\mathrm{N}$ terminal domain facing the nucleoplasm and the large $\mathrm{C}$-terminal domain extending into the perinuclear space $(33,70,78)$. Based on their highly conserved C-terminal SUN (Sad1/ UNC-84 homology) domain, five mammalian SUN proteins have been identified to date, with two of them (SUN1 and SUN2) located at the nuclear envelope. SUN1 and SUN2 are retained at the inner nuclear membrane by interaction of their $\mathrm{N}$-terminal domain with chromatin or other INM proteins, not all of which are known $(48,70,75,167,204)$. While localization of SUN2 is (at least in part) dependent on lamins A/C, SUN1 localization does not require lamins A/C or lamin B1 $(33,70,75,145)$, even though both SUN1 and SUN2 can directly bind to these lamin isoforms (33). Consequently, depletion of lamins does not increase the lateral mobility of SUN1 in fluorescence recovery after photobleaching (FRAP) experiments (75). This latter report is in contrast to more recent findings that lack of lamin A/C increases mobility of SUN1 and 2 and that A-type lamins, together with SUN2, anchor nesprin-2 at the nuclear membrane (141). Haque and colleagues (71) recently identified a novel binding region with SUN1 responsible for the association with the nuclear lamina that 
does not interact significantly with known binding partners, suggesting additional, yet to be identified binding partners. These could include nuclear pore complex proteins (118). Overexpression of SUN1 reveals that binding sites for SUN1 at the nuclear envelope are easily saturated, resulting in mislocalization to the endoplasmic reticulum and the cytoplasm (70). Taken together, this studies help form an evolving picture of the nuclear envelope, and how nuclear envelope proteins closely cooperate to facilitate nuclear-cytoskeletal coupling. At the same time, it is apparent that this image is still incomplete. Many important binding partners are yet to be identified, and even for the already discovered proteins, their function and interaction maps often remain incompletely defined, stimulating further research in this exciting area.

\section{Nuclear deformations under physiological stress/strain}

As illustrated in the sections above, the nucleus is tightly coupled to the surrounding cytoskeleton, which in turn is physically connected to the extracellular matrix and neighboring cells through integrins and other cell surface receptors. Therefore, mechanical deformations of the tissue are directly transmitted to the nucleus, with the potential to result in significant nuclear deformations. Such induced nuclear deformations can have important consequences on cellular functions. Through mechanisms yet incompletely understood, changes in nuclear shape are often directly correlated with altered gene expression in cells. For example, studies with micropatterned surfaces to modulate the cellular environment revealed that collagen synthesis correlated more strongly with nuclear shape than with cell shape (182). Similarly, changes in nuclear organization can modulate cellular and tissue phenotype in mammary epithelial tissue morphogenesis (113), and compression-induced shapes changes in chondrocyte nuclei closely correlate with changes in cartilage composition and density (67). These examples highlight the importance of nuclear mechanics and mechanically induced deformations on cell and tissue function. Before we discuss examples of nuclear deformations under mechanical stress in vivo and in vitro in more detail, it is helpful to briefly highlight the mechanical properties of the (interphase) nucleus, as these properties determine the extent of induced deformations when the nucleus is subjected to physical forces.

\section{Mechanical properties of the interphase nucleus}

Experiments on a wide variety of cells have shown that the interphase nucleus is significantly stiffer than the surrounding cytoskeleton. Most experiments yield values for the nuclear stiffness (i.e., elastic modulus) of $1-10 \mathrm{kPa}\left(1 \mathrm{kPa}=1,000 \mathrm{~N} / \mathrm{m}^{2}\right)$, with exact results depending on the examined cell type and the experimental technique used to obtain the measurements. $(25,67,98,188)$; overall, the measurements consistently demonstrate a 2 to more than 10-fold higher stiffness of the nucleus compared to the cytoskeleton. For example, measuring nuclear and cytoskeletal deformations in endothelial cells compressed between two parallel plates suggests an effective elasticity of the nucleus of $8 \mathrm{kPa}$ compared to $0.5 \mathrm{kPa}$ for the cytoplasm (25). Similar results were obtained in cells subjected to uniaxial strain (24) or in micropipette aspiration experiments of chondrocyte nuclei (67). In these experiments, the nucleus often behaves as a viscoelastic material, i.e., it displays a combination of instantaneous, elastic deformations and time-dependent, often plastic 
deformations $(36,67,159)$. In most cases, this time dependent behavior reaches a stable equilibrium with a few seconds $(46,161)$, while other experiments show continued nuclear deformation under an applied stress $(36,37,146)$, possibly reflecting differential nuclear organization, such as altered lamin $\mathrm{A} / \mathrm{C}$ densities at the nuclear envelope or interior and/or changes in chromatin organization.

Detailed analysis of nuclear deformations under applied stress reveals that the overall mechanical behavior of the nucleus is determined by the nuclear lamina and the nuclear interior; the lipid nuclear membranes that behave as a 2-dimensional fluid are considered to play only a minimal role in nuclear stiffness (160). The specific contribution of the nuclear lamina $v s$. the nuclear interior will depend on the given mechanical stimulation (e.g., stretching vs. compressing the cell), the particular cell type, differentiation state, and nuclear organization.

The nuclear lamina-Experiments on nuclei from Xenopus oocytes that enable researchers to separately determine the contributions of the nuclear lamina and chromatin to nuclear stiffness, have provided the base for our current understanding that the nuclear lamina acts as an elastic, load-bearing element that provides the majority of structural and mechanical support to the nucleus, particularly under tensile load application $(36,37,164)$. Accordingly, nuclei assembled in lamin-depleted Xenopus egg extracts are highly fragile (135) and nuclei from lamin A/C-deficient mouse embryo fibroblasts and myoblasts cells are significantly softer than nuclei from wild-type controls $(105,107)$. As reported above, nuclear strain experiments performed on a variety of mouse embryo fibroblast lines lacking different lamin isoforms or overexpressing these lamins indicate that lamins $\mathrm{C}$ and particularly lamin A are the main contributors of nuclear stiffness (105). Whereas lamin B1 deficient cells have normal nuclear mechanics, nuclei in cells lacking lamin $\mathrm{A}$ and $\mathrm{C}$ deform significantly more under strain application; cells lacking lamin A, but not lamin $\mathrm{C}$, have only modestly impaired nuclear mechanics, whereas cells expressing only lamin A, but not lamin $\mathrm{C}$, have in fact even stiffer nuclei than cells from wild-type littermates ( $\mathrm{J}$ Lammerding, unpublished observation). These findings are consistent with recent reports that A and B-type lamins form separate networks at the nuclear lamina (170) with distinct structural organization $(47,61)$. When human B-type lamins are ectopically expressed in Xenopus oocytes, they form a thin network of 8-10 nm fibers underlying the inner nuclear membrane; in contrast, ectopically expressed A-type lamins assemble thicker structures on top of the B-type lamin network (Fig. 4) and cause a dramatic stiffening of the oocyte nucleus $(60,164)$. Importantly, as the nuclear lamina is involved in nuclear-cytoskeletal coupling, mutations in lamins or other nuclear envelope proteins could alter force transmission between the nucleus and the cytoskeleton and thereby further affect nuclear deformation under externally applied loads.

The nuclear interior-The nuclear interior acts as a compressible, aqueous, sponge-like, viscoelastic material that increases in stiffness as it becomes compressed $(36,160)$. The majority of the nuclear interior is comprised of chromatin, and modifications of chromatin structure have been demonstrated to directly influence the physical properties of nuclei in micropipette aspiration experiments (146). Similarly, alterations in chromatin by divalent 
salts $(36)$ or upregulation of heterochromatin proteins $(127,146)$ reduce chromatin movements inside the nucleus and stiffen the chromatin. In addition to chromatin, proposed nucleoskeletal structures could also contribute to the mechanical behavior of the nuclear interior. Nuclear lamins, particularly lamins A and C, form stable structures in the nuclear interior and are in constant exchange with the nuclear lamina (20). The presence of these internal lamins and lamin binding proteins such as LAP2a could provide structure and organization within the nucleoplasm. Importantly, it appears that there is significant interplay between the diverse components of the nuclear interior and periphery. For example, loss of lamins A and C or lamin A mutations associated with Hutchinson-Gilford progeria syndrome cause significant alterations in chromatin organization, characterized by a loss of peripheral heterochromatin, which could in turn affect nuclear mechanics. Similarly, the nucleoplasmic protein LAP2a has been shown to modulate localization of lamin $\mathrm{A} / \mathrm{C}$ between the nuclear periphery and interior, thereby modulating nuclear organization and cellular function $(63,133)$.

\section{Nuclear deformations in vivo and in vitro}

Researchers have long recognized the strong dependence of nuclear shape and cellular morphology in vivo and in vitro. For the most part, these observations have been/are derived from images of fixed tissues and cells; however, more recently, live cell imaging has enabled the observation of nuclear deformations in real time, giving researchers an opportunity to study the dynamic processes of nuclear deformations in cells and tissues under an applied mechanical load. Much of the in vivo and in situ observations have traditionally focused on nuclear deformations in chondrocytes and in cancer cells; nonetheless, considerable research has been carried out in vitro on cells highly relevant to respiratory physiology, including airway and vascular smooth muscle cells and endothelial cells.

Nuclear deformations in vivo and in situ-While changes in nuclear shape are routinely used in the analysis of fixed tissues by pathologists, measuring dynamic nuclear deformations in vivo remains extremely challenging. Langevin and colleagues have provided stunning observations from subcutaneous tissue in mice that had been mechanically stretched in vivo or locally stimulated by inserting and rotating acupuncture needles, resulting in localized application of large tissue strain $(108,109,178)$. Their data reveal mechanically induced spreading of fibroblasts associated with flattening of the nucleus and formation of nuclear invaginations containing alpha smooth muscle actin (Fig. 5). Recently, real-time in vivo imaging has found increased application in elucidating the cellular processes underlying metastasis. By using GFP fused to histones and applying multi-photon imaging, researchers have succeeded in visualizing nuclear deformations during migration of cancer cells in living mice (79). Nuclei could be observed to elongate to squeeze through narrow blood vessels and to deform during extravasation, suggesting a potential role of nuclear mechanics in cancer progression.

Some of the most detailed studies of nuclear deformations have been obtained from in situ experiments of chondrocytes in articular cartilage explants. During compression, chondrocyte nuclei undergo a significant decrease in height and volume (Fig. 6), which was 
at least in part mediated by the actin cytoskeleton $(66,67,110)$, and changes in nuclear shape could directly contribute to expression of cartilaginous genes (88).

Nuclear deformations during strain application in vitro-In contrast to the above experiments, studying cells cultured in vitro allows for imaging of nuclear dynamics with high temporal and spatial resolution. Studying the cellular/nuclear response to mechanical strain application is highly relevant to the respiratory system. During respiration, cells lining the airways are regularly exposed to significant circumferential tissue strain; similarly, airway smooth muscle cells, vascular smooth muscle cells, and vascular endothelial cells are subjected to repetitive vessel strain; in addition, intercoastal muscles involved in inhalation and expiration, rhythmically contract and relax during inhalation and expiration, subjecting nuclei in these muscles to significant physical stress. Substrate strain experiments provide a useful model to mimic these physiological conditions. In these experiments, cells are plated on thin, transparent substrates (e.g., silicone membranes) and imaged before, during, and after application of uniaxial or biaxial strain to the elastic substrate. The cytoskeleton, which is tightly coupled to the substrate via cell adhesion receptors, is stretched to similar extent $(\sim 80-100 \%)$ as the underlying substrate; in contrast, the stiffer nucleus, which is surrounded by the cytoplasm, deforms much less. In the case of endothelial cells or fibroblasts, the nuclear deformation is on the order of 10-30\% of the applied substrate strain, again demonstrating that the nucleus is significantly stiffer than the surrounding cytoskeleton (24, $25,59,105,107)$. Nonetheless, assuming physiological relevant tissue/substrate strains of 10 to $20 \%$, this corresponds to nuclear elongation of 1 to $6 \%$, which could be sufficient to cause substantial deformations within the nuclear interior. Inhomogeneous distribution of the nuclear strain throughout the nucleus could result in locally even higher strain values, possibly causing changes in chromatin structure and altered accessibility to transcription factors.

As an alternative to globally applied substrate strain, forces can be applied locally to the cell surface via beads or microneedles covered with extracellular matrix molecules $(90,120)$. Experiments on airway vascular smooth muscle cells revealed that the induced nuclear deformations are highly dependent on the cytoskeletal pre-stress, i.e., the contractile status of the cells: Increased cellular pre-stress resulted in increased induced nuclear deformations, indicating improved stress propagation, while reduced pre-stress caused an abolished response (90).

Nuclear changes in response to shear stress-In addition to repetitive vessel strain, vascular endothelial cells are exposed to varying levels of fluid shear stress. Endothelial cells have been long known to be exquisite mechanosensors, responding to variations in fluid shear stress with activation of biochemical pathways and activation of mechanosensitive genes (41). Many of these signals, including the release of nitric oxide (NO) or expression of specific cell surface receptors, are used to communicate with underlying smooth muscle cells or to allow circulating cells such as leukocytes to bind to endothelial cells and exit the blood vessel. This mechanotransduction response is a critical protective mechanism against atherosclerosis and important for the normal maintenance of blood vessels $(41,68)$. The molecular mechanisms by which cells sense their physical 
environment and transducer it into biochemical signals, generally referred to as mechanotransduction, have been the focus of intense research over the past decades, and while much progress has been made, many unknowns remain. It is now well established that many of the cellular processes involved in this mechanotransduction process originate in the cytoskeleton or on the cell surface, including stretch sensitive ion channels, the glycocalyx, and cell adhesion sites $(41,68)$; on the other hand, involvement of the nucleus in the mechanotransduction process has often been proposed, but never firmly documented (39). Nonetheless, the importance of nuclear mechanics to the physiological response to shear stress is supported by recent findings that nuclei of endothelial cells subjected to fluid shear stress show persistent changes in shape and stiffness, acting as a stress-bearing organelle $(37,46,122)$. In endothelial cells exposed to fluid shear stress, the nucleus itself is subjected to significant amounts of force. It was proposed that alignment of vascular endothelial cells in the direction of flow, as consistently seen in vitro and in vivo, could be explained by cells trying to minimize the force acting on the nucleus (76). Consequently, alterations in nuclear structure and stiffness due to mutations or disease could have significant affects on endothelial mechanotransduction and cell function (38).

\section{Techniques to measure nuclear mechanics}

Early experimental techniques to probe the physical properties of the nucleus and the effect of disease causing mutations included observing nuclear fragility after heat-shocked treatment $(147,192)$ or studying nuclear deformations in adherent cells as they detached from their substrate (94), but neither method can produce consistent mechanical loading conditions. Consequently, these techniques have given rise to more sophisticated experimental assays specifically designed or adapted to measure nuclear mechanics, including micropipette aspiration, atomic force microscopy, or substrate strain experiments. As a general principle, these techniques use various means to mechanically perturb intact cells or isolated nuclei with a known force or applied deformation while simultaneously visualizing the induced nuclear deformation. The mechanical properties of the nucleus can then be inferred from the relationship between applied force and induced deformation. Alternatively, the effects of biochemically modifications, e.g., mutations in nuclear envelope proteins or reduced expression of these proteins, can be directly determined by comparing the induced nuclear deformation between various cell lines under the same applied mechanical load or deformation. Overviews of the most commonly used techniques are summarized below and in Fig. 7. For a more detailed review, the reader is referred to (104).

Isolated nuclei vs. intact cells-As described in more detail in the following sections, experimental techniques to measure nuclear mechanics vary between studying nuclei in intact, living cells and probing isolated nuclei. The major advantage of studying nuclei within living cells is that normal nuclear and cytoskeleton architecture as well as the chemical composition of the nucleoplasm and cytoplasm, are preserved, thereby assuring to reflect physiological conditions. The major limitation of working with intact cells is that measurements of the physical properties of the nucleus may be influenced by the surrounding cytoskeleton, as the nucleus is not directly accessible to the probe. In contrast, experiments on isolated nuclei can directly apply precisely controlled forces to the nucleus, for example through micropipette aspiration or atomic force microscopy, and measure 
induced nuclear deformations with high precision. The trade off is that nuclei may be damaged during the isolation procedure, particularly when examining more fragile nuclei as seen with certain lamin mutations, and that intracellular conditions, including the correct biochemical environment, are difficult to maintain. In particular, chromatin structure and configuration are very sensitive to concentrations of divalent cations such as $\mathrm{Ca}^{2+}$ and $\mathrm{Mg}^{2+}$, so that nuclear shape and mechanics dramatically change depending on the particular buffer used (36).

Micropipette aspiration-One of the most frequently used techniques to probe nuclear mechanics is micropipette aspiration $(36,37,40,46,67,146,159,161)$. This technique can be applied to isolated nuclei and to living cells in which the cytoskeletal structure has been disrupted by cytochalasin treatment, allowing the nucleus to be partially drawn into the micropipette. Common to all nuclear micropipette aspiration experiments is that the nucleus is gently aspirated into a glass micropipette with an inner diameter of $\sim 3$ to $6 \mu \mathrm{m}$. Using precisely controlled aspiration pressure (typically 1-7 kPa), parts of the nucleus are further drawn into the micropipette opening. During this process, nuclear deformations are monitored by videomicroscopy. Assuming that the nucleus can be modeled as a (visco-) elastic solid, the creep compliance, $J(t)$, of the nucleus (i.e., the inverse of the nuclear stiffness) can be calculated from the aspirated tongue length, the applied aspiration pressure, and some geometrical factors such as the micropipette diameter based on the following equation:

$$
J(t)=\frac{2 \pi \Phi}{3} \frac{1}{P} \frac{\Delta L(t)}{R_{p}}
$$

In this equation, $\Phi$ denotes a shape factor that depends on the micropipette wall thickness (here, $\Phi=2.1 ;(181)), P$ is the applied aspiration pressure, $\Delta L(t)$ is the aspirated length at time, and $R_{\mathrm{p}}$ is the pipette radius $(36,181)$.

Micropipette aspiration can be supplemented by imaging fluorescently labeled components of the nucleus, e.g., lamins, histones, or the nucleolus, with a confocal microscope. For example, imaging nuclei with GFP-lamins incorporated into the nuclear lamina enables quantification of the nuclear strain distribution during micropipette aspiration, as the fluorescence intensity decreases with strains due to the increased spacing between fluorophores stably incorporated into the lamina (Fig. 8) (161). Furthermore, micropipette aspiration can be easily applied to the enormous Xenopus oocytes, in which chromatin comprises only a small fraction of the total volume, thereby enabling direct measurements of the contributions from the nuclear lamina and the chromatin to nuclear stiffness (37).

Micropipette aspiration offers the advantage to directly probe the physical properties of the nucleus. The main limitations of this technique are that it requires isolated nuclei or at least cytoskeletal disruption when studying nuclei in intact cells, and that the force application may not adequately resemble physiological conditions, where tensile forces are transmitted to the nucleus through the cytoskeleton. 
Atomic force microscopy and micro-indentation-Atomic force microscopy (AFM) and microindentation experiments are routinely used to study the mechanical properties of adherent cells, and have recently found application in measuring nuclear stiffness. In these experiments, isolated nuclei attached to a rigid substrate are (locally) indented with a microscopic probe, while simultaneously measuring the applied force and the indentation depth. In the case of AFM, the probe is a cantilever with a conical, pyramid shaped, or spherical tip, and the resulting forces are calculated from the deflection of the cantilever. In the case of microindentation, the cell or nucleus is probed with a cylindrical probe (with a diameter of a few micrometer) or a flexible plate, and the forces measured by sensitive force transducer attached to the probe (19).

The interpretation of AFM or microindentation experiments often requires the use of analytical models to infer material parameters such as the apparent Young's modulus, $E$, from the force-indentation curves. Even though these models typically make simplifying assumptions of the nuclear structure and material (e.g., assuming homogeneous, isotropic, linear, elastic behavior), the predicted curves often match the experimental data quite well (164). Furthermore, force-indentation curves can be directly compared between different cell lines or conditions (e.g., knock-out vs. control) without modeling to infer stiffness parameters, provided that probe and sample geometries are comparable. To date, AFM and cellular compression devices have been successfully used to study nuclear deformations in chondrocytes $(66,67)$, fibroblasts $(19,183)$, kidney epithelial cells $(36)$, endothelial cells (25), and nuclei isolated from Xenopus oocytes (164).

The great advantage of the AFM technique is that it provides direct high resolution measurements of the applied forces and the induced deformations in isolated nuclei. Limitations of this technique include the interpretation of the results, which often requires simplifying assumptions on the nuclear structure and geometry, the dependence of the chosen probe, which might measure local as opposed to global nuclear stiffness, possible effects of the underlying stiff substrate in case of large indentations, and the requirement to use isolated nuclei.

One advantage of the cell compression or micro-indentation method compared to AFM experiments is that is uniformly applies a compressive force to the entire nucleus or cell, whereas AFM experiments utilizing conical or pyramid shaped tips apply a highly localized force (this can be overcome by using "tip-less" AFM probes or large microscopic beads attached to the AFM tip). Furthermore, the microindentation technique is suitable to probe nuclear mechanics in intact cells in their normal cellular environment and even works on suspension cells and only weakly adherent cells. However, the nuclear deformations observed within intact cells are affected by the cytoskeleton surrounding the nucleus, complicating the analysis of the results.

Substrate strain experiments-When cells are stretched, the resulting forces are transmitted through the cytoskeleton to the nucleus. For an elastic material, the induced strain is inversely proportional to the material stiffness (Young's modulus) and increases linearly with the applied stress, i.e., the force per area (Hooke's law). Within the cell, near the nucleus, the same force acts on the cytoskeleton and nucleus; as the nucleus is typically 
much stiffer than the surrounding cytoskeleton, the induced nuclear deformations are expected to be much smaller than those of the cytoskeleton. Thus, even without knowing the exact force levels transmitted through the cytoskeleton, one can determine the relative stiffness of the nucleus to the cytoskeleton from the induced nuclear and cytoskeletal strain under a given applied substrate strain. In a typical strain experiment, cells are cultured on thin, elastic, transparent substrates coated with extracellular matrix molecules to promote cell spreading and adhesion. Uniform uniaxial or biaxial strain is subsequently applied to the substrate while monitoring induced nuclear and cellular deformations before, during, and after strain application on a microscope. Nuclear stiffness can then be inferred from the induced nuclear strain relative to the applied substrate strain (which closely matches the cytoskeletal strain).

Substrate strain experiments were first applied by Caille and colleagues $(24,25)$ to quantify nuclear stiffness relative to the surrounding cytoskeleton $(24,25)$. Recently, these experiments have found extensive use in evaluating the importance of nuclear envelope proteins for nuclear stiffness $(105-107,191)$. Compared to micropipette aspiration and AFM experiments that work one cell at a time, cellular strain experiments allow simultaneously probing of many cells at once. As a consequence, the same experimental technique can be used to collect cell lysates or mRNA to study mechanotransduction events in cells exposed to mechanical strain. This is particularly relevant as uniaxial or biaxial strain application closely resemble the physiological loading conditions found in muscle, vascular or airway smooth muscle cells, or tissue fibroblasts, thereby allowing important insights into the consequences of altered nuclear mechanics in these tissues. Another advantage of this technique is that it is performed on intact cells under physiological conditions, thereby maintaining the normal cellular and nuclear structure and architecture. The main limitations are that nuclear deformations depend on cell adhesion and cytoskeletal structure, requiring careful evaluation of each cell, and that experiments are limited to well adherent cells that can withstand significant strain application (typically 5-25\%).

Nuclear microrheology-Common to all of the approaches discussed above is that they rely on external force application to the nucleus, resembling the typical loading conditions in most cells. As these experiments interpret the induced nuclear deformations, they provide important information on the overall mechanical behavior of the nucleus. However, occasionally, it can be desirable to probe the physical properties of the nuclear interior, for example to measure the stiffness of chromatin in situ, which is not possible with the aforementioned techniques. In this case, active and passive microrheology can be used to study the local mechanical (rheological) properties of the nuclear interior. In active microrehology, a magnetic bead is inserted into the nucleus and subjected to precisely controlled forces from magnetic or optical tweezers (44). The rheological properties of the surrounding nucleoplasm can then be inferred from the induced bead displacement under a given force. In passive microrheology, submicrometer-sized beads are injected into the nucleus; the stiffness of the nucleoplasm surrounding the bead is then inferred from the thermal fluctuation (mean-squared displacement) of the beads undergoing Brownian motion (185). 
Active microrheology provides a powerful combination of precisely controlled force application and high resolution imaging of the induced bead deflection. The major limitations are the disruptive insertion of the relatively large magnetic bead into the nucleus and the fact that the stiffness measurement is obtained at only a single spot, making it subject to local variations. Compared to active microrheology, which uses beads of $\approx 500$ $1,000 \mathrm{~nm}$ diameter, passive microrheology offers the advantage that the smaller bead size $(\approx 100 \mathrm{~nm})$ used in these experiments causes less perturbation to the cell or the nucleus. However, results from this technique can be very sensitive to bead size: Beads that are not sufficiently entangled in the surrounding nuclear matrix/chromatin can move more freely, resulting in apparently lower nuclear stiffness values that represent the viscosity of the nucleoplasm rather than that of the surrounding matrix. A common limitation of both techniques is that the act of microinjecting foreign bodies into the nucleus could perturb nuclear structure and integrity and thereby affect experimental results.

\section{Nuclear mechanics in development and differentiation}

In cell and developmental biology, stem cells and their nuclei are often described as "plastic", referring to their ability to differentiate into multiple lineages and activate diverse gene expression profiles (13). This plasticity in gene expression in (embryonic) stem cells is associated with distinct chromatin structure and epigenetic modifications compared to differentiated cells $(10,127)$. Only recently has it become apparent that these changes are also reflected in altered mechanical properties of stem cell nuclei $(9,146)$.

\section{Stem cells}

While nucleosomal proteins, particularly core histones (i.e., H2A, H2B, H3, H4), form stable complexes with chromatin in differentiated cells, the mobility of these nucleosomal proteins is significantly increased in embryonic stem cells $(9,127)$, suggesting a more accessible chromatin structure that could facilitate transcriptional activation. Micropipette aspiration experiments on human adult stem cells and hematopoietic stem cells demonstrate that nuclear stiffness dramatically increases during induced neurectodermal differentiation of these cells (146). Within 6 days of differentiation, the nuclear stiffness of human embryonic stem cells increases 6-fold, reaching values typical for fully differentiated cells such as embryonic fibroblasts (146). Time-lapse imaging of mouse embryonic stem cells and primary mouse embryonic fibroblasts reveals that embryonic stem cells show severe dynamic fluctuations in nuclear shape, again suggesting that stem cell nuclei also have increased physical plasticity. Interestingly, the stiffness of human hematopoietic stem cells, which have lower developmental plasticity than embryonic stem cells, falls between that of undifferentiated embryonic stem cells and fibroblasts (146). As discussed in more detail below, the reduced nuclear stiffness of embryonic and hematopoietic stem cells can most likely be attributed to two distinct contributions: (i) Changes in lamin expression and (ii) altered chromatin structure

Altered lamin expression in embryonic stem cells-In contrast to most differentiated cells, embryonic stem cells do not express any A-type lamins, and hematopoietic stem cells express only lamin C, not A $(166,177)$. As lamins A and C are the 
main contributors to nuclear stiffness, particularly lamin A (105), these differences in lamin expression alone could be sufficient to explain the reduced nuclear stiffness in embryonic and hematopoietic stem cells. Supporting this idea is the finding that reducing lamin A/C expression in human epithelial cells by shRNA mediated RNA interference resulted in nuclear stiffness comparable to that of hematopoietic stem cells (146).

Altered chromatin mechanics in embryonic stem cells-Embryonic stem cells have an increased mobility of core nucleosomal proteins, possibly reflecting a more accessible chromatin configuration $(10,127)$. Detailed analysis of intranuclear deformations during micropipette aspiration of epithelial cells in which lamin $\mathrm{A} / \mathrm{C}$ expression had been reduced by RNA interference revealed that chromatin has fluidic-like viscoelastic properties consistent with the compliance of single chromatin fibers (146). It will be interesting to conduct a direct comparison between the viscoelastic properties of embryonic stem cells and terminally differentiated cells in future experiments.

Importantly, the contribution of lamins and chromatin organization might not be independent factors, as loss of A-type lamins results in loss of peripheral heterochromatin, suggesting a direct involvement of A-type lamins in chromatin organization.

Granulocytes-While most differentiated cells express at least one of the A-type lamins, neutrophils stand out as an example of differentiated cells that reduce the expression of Atype lamins and other nuclear envelope proteins to optimize nuclear shape and structure for their cellular function. Neutrophils are recruited to sites of infections, where they exit the bloodstream to enter the affected tissue. These processes require neutrophils to squeeze through narrow openings only a few micrometers wide, i.e., smaller than the nuclear diameter. During granulopoiesis, i.e., the differentiation of promyelocytes into mature neutrophils, cells develop increasingly lobulated nuclei; this modulation in nuclear morphology is associated with almost complete loss of lamin $\mathrm{A} / \mathrm{C}$ expression and increased expression of lamin B receptor (LBR)(82, 140, 205). These adaptations result in a highly malleable nucleus, making it ideally suited for transendothelial migration and passage through narrow tissue spaces (140). Recent findings suggest that the cellular plasticity might be further enhanced by the downregulation of cytoskeletal proteins such as vimentin and proteins involved in nuclear-cytoskeletal coupling (139). As in the case of embryonic stem cells, these changes are also associated with alterations in chromatin structure (138), again suggesting a tight mechanistic link between nuclear envelope composition and chromatin organization.

\section{Altered nuclear mechanics in disease}

The discovery that mutations in the LMNA gene and associated nuclear envelope proteins are responsible for a wide range of human diseases collectively called laminopathies-or more generally nuclear envelopathies-has propelled research on the nuclear envelope to the forefront of scientific interest, documented by a steep increase in publications over the past 10 years. Despite many advances in the field, the molecular mechanisms underlying the multifaceted disease phenotypes remain unclear, in part because the multiple functions of nuclear envelope proteins are still incompletely defined. 
This knowledge gap also factors into a second class of human diseases that could be linked to changes in nuclear envelope composition: Cancer. While it is well established that cancer cells are characterized by nuclear shape abnormalities 225) and recent reports suggest that various cancers are associated with altered expression levels of nuclear lamins $(2,31,91$, $189,198)$, it remains unclear whether such changes in nuclear shape and organization can directly contribute to cancer progression.

\section{Nuclear envelopathies}

In the broadest definition, nuclear envelopathies are human diseases caused by mutations in nuclear envelope proteins such as lamins, emerin, or lamin B receptor (LBR). In the 1990's, mutations in the genes encoding emerin (Emd) and A-type lamins (LMNA) were first identified to cause the X-linked and autosomal form of Emery-Dreifuss muscular dystrophy, respectively $(11,15,134)$. Subsequently, a plethora of additional mutations have been identified in the $L M N A$ gene, causing a wide spectrum of diseases referred to as laminopathies (reviewed in (202)). The laminopathies can be broadly grouped into four groups based on the affected tissues, with at times significant overlap between them. The first group, diseases affecting skeletal and cardiac muscle, includes autosomal dominant Emery-Dreifuss muscular dystrophy (15), X-linked Emery-Dreifuss muscular dystrophy (11, 134), limb-girdle muscular dystrophy type 1B (131), dilated cardiomyopathy with conduction defects (53), and - to a lesser extent-Charcot-Marie-Tooth disorder (43). Laminopathies affecting adipose tissue are Dunnigan-type familial partial lipodystrophy (26, 169) and Mandibuloacral dysplasia (137). The third group, comprised of diseases affecting the central or peripheral nervous system, includes Charcot-Marie Tooth disorder (43), adultonset autosomal dominant leukodystrophy, which is caused by a duplication of the LMNBI gene (143), and autosomal recessive cerebellar ataxia, which is linked to mutations in the nesprin-1 (SYNE1) gene (65). Finally, the fourth group consists of laminopathies with a progeroid phenotype, affecting multiple tissues. Hutchinson-Gilford progeria syndrome and atypical Werner's syndrome fall into this category $(28,42,51)$. To date, more than 300 different mutations have been identified in the LMNA gene, with new mutations frequently added to the list. The latest updates can be found at the LMNA mutations database at http:// www.umd.be/LMNA/. Interestingly, the phenotype and severity of laminopathies can vary extensively, even for identical mutations and among siblings (16). The majority of the mutations identified so far are linked to Emery-Dreifuss muscular dystrophy (57). Recently, it was shown that Emery-Dreifuss muscular dystrophy can also be caused by mutations in the nuclear envelope proteins nesprin- 1 and nesprin-2 $(156,210)$, suggesting that defects in nuclear-cytoskeletal coupling could contribute to the disease mechanism. This notion is further supported by findings that mice lacking A-type lamins $\left(\mathrm{Lmna}^{-{ }^{-}}\right)$or expressing a mutation linked to Emery-Dreifuss muscular dystrophy $\left(\right.$ Lmna $\left.^{\mathrm{H} 222 \mathrm{P} / \mathrm{H} 222 \mathrm{P}}\right)$ fail to properly recruit and anchor myocyte nuclei at the neuromuscular junctions (124) and also display defects in nuclear-cytoskeletal coupling in vitro (69).

Pelger-Huet Anomaly is a separate disorder caused by autosomal dominant mutations in the lamin B receptor $(L B R)$ gene (80). Individuals affected by Pelger-Huet anomaly have neutrophils with hypolobulated nuclei and abnormal chromatin organization, but lack a clinical phenotype (Fig. 9). In the rare cases of homozygous expression of the mutant LBR 
protein, neutrophils have ovoid shaped nuclei (as opposed to the normally highly lobulated shape in these cells) and display varying degrees of developmental delay, epilepsy, and skeletal abnormalities (80).

Abnormal nuclear mechanics in muscular laminopathies-Despite the fact that Atype lamins are expressed in almost all differentiated cells, many of the laminopathies have tissue-specific phenotypes, with the majority of the mutations affecting striated muscle. Furthermore, several other laminopathies have skeletal or cardiac muscle involvement in addition to their primary phenotype, e.g., lipodystrophies that are associated with cardiac and skeletal muscle alterations (186) or a phenotype combining progeria and myopathy (100). Two hypotheses, neither mutually exclusive, have emerged to explain how mutations in lamin proteins could cause the diverse disease phenotypes reflected in the laminopathies $(18,22,93)$. The "gene-regulation hypothesis" proposes that perturbed gene regulation may underlie the development of different disease phenotypes, while the "structural hypothesis" proposes that mutations in the lamin proteins render the nucleus more fragile, causing cell death and eventually disease in mechanically stressed tissues such as skeletal or cardiac muscle $(18,22,92)$. Most ongoing research on the nuclear envelope continues to revolve around these two broad hypotheses, which are based on the following observations.

Mutations that cause muscular laminopathies often encode internal residues that result in the disruption of the protein structure, affecting the ability of lamins to dimerize, polymerize, extend filaments, or to interact with other nuclear proteins $(18,195)$. Evidence of fragmented nuclei has been reported in skeletal muscle fibers from Emery-Dreifuss muscular dystrophy patients $(55,56,192)$ and in fibroblasts from laminopathy patients following heat-shock treatment $(147,192)$. In lamin A/C-deficient $\left(\mathrm{Lmna}^{-/-}\right)$mice, cardiac myocytes have significantly increased ultrastructural nuclear damage compared to hepatocytes $(136,179)$, and $\mathrm{Lmna}^{-/-}$fibroblasts have decreased nuclear stability and increased nuclear fragility $(19,107)$. Importantly, the structural role of lamin A/C is not limited to the nucleus itself. Desmin filaments are often disrupted and detached from the nuclear surface in $\mathrm{Lmna}^{-/-}$cardiac myocytes (136), and $\mathrm{Lmna}^{-/-}$mouse embryo fibroblasts have decreased cytoskeletal stiffness and apparently defective nuclear-cytoskeletal connections $(19,107)$. Similarly, emerin-deficient mouse embryo fibroblasts have abnormal nuclear envelope mechanics in micropipette aspiration experiments (161), even though overall nuclear stiffness and fragility appear normal in these cells (106). Muscle biopsies from Emery-Dreifuss muscular dystrophy patients show that almost $25 \%$ of the nuclei have structural abnormalities or are damaged (55), and $\approx 0.5 \%$ of cardiac myocytes stain positive for apoptotic markers in 6-week old $\mathrm{Lmna}^{-/-}$mice (136). Experiments on mouse embryonal fibroblasts and myoblasts from $\mathrm{Lmna}^{-/-}$animals show that these cells have decreased nuclear stiffness (Fig. 10), increased nuclear fragility, and an increased sensitivity to mechanical strain $(17,107)$. Importantly, functional loss of lamin $\mathrm{A} / \mathrm{C}$ also causes defects in cell signaling, proliferation, and differentiation. As described in previous sections, A-type lamins and emerin interact with chromatin and several transcriptional regulators $(7,49,72$, $73,85,86,97,119,128,129,142,197)$. As a consequence, lamins $\mathrm{A}$ and $\mathrm{C}$ and emerin are critical for differentiation and regeneration of human and mouse muscle cells in vivo and in vitro $(5,57,125)$ and expression of mutant forms of lamin A associated with Emery- 
Dreifuss muscular dystrophy inhibits in vitro differentiation of C2C12 myoblasts $(54,121)$. The fact that the gene regulation and structural hypothesis are not mutually exclusive but at least in part interdependent is further illustrated by the findings that $\mathrm{Lmna}^{-/-}$fibroblasts have reduced activation of mechanosensitive genes in response to mechanical strain and impaired transcriptional activation (107), resulting in increased necrosis and apoptosis under strain $(19,106,107)$. Defects in mechanotransduction have also been demonstrated in vivo, as $\mathrm{Lmna}^{-/-}$mice lack a compensatory hypertrophic response despite developing severe dilated cardiomyopathy (136) and $L m n a^{+/-}$mice have an attenuated hypertrophic response to cardiac pressure overload induced by aortic banding (35). Thus, changes in nuclear structure and function could contribute both to increased cellular sensitivity to mechanical strain and to altered transcriptional regulation. Furthermore, since the mechanical environment can direct stem cell differentiation (50), impaired mechanotransduction signaling could contribute to the differentiation defects seen in $\mathrm{Lmna}^{-/-}$myoblasts $(27,57)$.

In summary, mutations causing muscular laminopathies appear to resemble (partial) functional loss of A-type lamins, resulting in reduced nuclear stiffness and increased nuclear fragility $(105,179)$, thereby leading to increased cellular sensitivity to mechanical stress.

This increased susceptibility to mechanical stress is aggravated by further defects in nuclearcytoskeletal coupling, mechanotransduction signaling, tissue regeneration, cell proliferation, and cell differentiation $(30,57,107,111,112,136)$, resulting in the progressive loss of muscle cells and an impaired ability to repair the damage.

\section{Altered nuclear mechanics in Hutchinson-Gilford progeria syndrome-}

Hutchinson-Gilford progeria syndrome (HGPS) is a rare segmental aging syndrome caused by autosomal dominant mutations in the LMNA gene. Most cases of HGPS results from a silent mutation at position G608, which partially activates a cryptic splice donor site and leads to a truncated form of lamin A (progerin) that is abnormally processed and remains farnesylated $(42,51)$. Affected individuals appear normal at birth, but soon afterwards display failure to thrive, bone and joint abnormalities, alopecia (hair loss), and sclerotic skin. Children with HGPS develop severe cardiovascular phenotypes that result in lethal strokes or myocardial infarction at a median age of 13 to 14 years.

Interestingly, impaired nuclear mechanics and mechanotransduction signaling could also play an important role in the pathophysiology of HGPS, as increased cellular sensitivity to hemodynamic shear stress or vascular vessel strain could contribute to the increased risk of arteriosclerosis in HGPS patients $(175,176)$. Arteriosclerosis is the leading cause of death in HGPS patients (3), and ultrastructural analysis of vascular tissue from HGPS patients reveals extensive loss of vascular smooth muscle cells and an unusual susceptibility to hemodynamic stress $(175,176)$, while vascular endothelial cells appear unable to preserve intimal integrity after injury (6). When fibroblasts from HGPS patients are subjected to repetitive mechanical strain, they are more susceptible to cell death and lack the normal proliferative response (191), suggesting that altered cellular sensitive to mechanical stress could be responsible for the progressive loss of vascular smooth muscle cells in HGPS or at least add to other cellular defects seen in HGPS such as genetic instability and premature cellular senescence $(32,117,130,187)$. It is noteworthy that in contrast to lamin A/Cdeficient cells, skin fibroblasts from patients with HGPS develop increasingly stiffer nuclei 
in culture $(40,191)$. The increased nuclear stiffness is likely caused by progerin accumulating at the nuclear envelope and the more stable incorporation of progerin into the nuclear lamina (40). These defects can be reversed by treatment with farnesyltransferase inhibitors, indicating that this lipid anchor is responsible for the increased nuclear envelope recruitment and stability of progerin. These effects are further exacerbated by the ability of progerin to alter the segregation of A-type and B-type lamin homopolymers (47) and to reduce the diffusional mobility of wild-type lamins (40).

However, the abnormal mechanical sensitivity cannot be directly attributed to changes in nuclear stiffness, as the increased sensitivity was already apparent in cells that still had normal nuclear stiffness and also persisted after treating cells with farnesyltransferase inhibitors which normalized nuclear stiffness in HGPS fibroblasts (191).

Even though vascular smooth muscle cells are most affected in the cardiovascular phenotype of HGPS, recent evidence suggest that the phenotype could also be, at least in part, mediated by endothelial cells, as endothelial cells expressing progerin have an impaired response to fluid shear stress $(38,154)$. The importance of (normal) nuclear mechanics to the physiological response to shear stress is further supported by the recent finding that nuclei of endothelial cells subjected to fluid shear stress show persistent changes in nuclear shape and stiffness, acting as a stress-bearing organelle $(37,46)$. Mechanotransduction is a critical protective mechanism against atherosclerosis (41), and impaired gene activation in response to mechanical stimulation could further exacerbate the effect of nuclear mechanical deficiencies in vascular cells. A recent gene array analysis found that expression of a large number of transcription factors and extracellular matrix proteins was significantly altered in HGPS fibroblasts, including many genes implicated in arteriosclerosis that changed 2- to 12fold (34); as a cautionary note, these experiments were performed in exponentially growing cultures without any mechanical stimulation, and further studies are warranted. Defective nuclear mechanics and mechanotransduction could not only increase the risk of arteriosclerosis but could also contribute to pathological effects in other mechanically loaded tissue such as bone abnormalities and skeletal muscle dystrophy, defects typically seen in HGPS patients.

As in the case of muscular dystrophies, progerin expression also alters the differentiation potential of stem cells, and depletion of functional stem cells, either by cell death or the loss of their "stemness", has been proposed as a third mechanistic hypothesis for laminopathies (126). The involvement of nuclear mechanics in this phenotype has yet to be addressed.

\section{Cancer}

Aberrations in gross nuclear morphology, such as increase in nuclear size, changes in shape, and loss of nuclear domains, are often used to identify cancerous tissue (215). In breast cancer cells, nuclear morphology correlates more strongly with a cancerous phenotype than cellular morphology $(12,149)$. Such changes in nuclear morphology in cancer cells are often associated with distinct changes in expression of nuclear structural proteins; this nuclear "pleomorphism" is associated with increased susceptibility and metastatic potential in a variety of cancers $(14,23,114,155,171)$. For example, lamins $\mathrm{A}$ and $\mathrm{C}$ are over-expressed in ovarian cancers compared to control cells (91) and provide a risk biomarker in colorectal 
cancer (198); increased levels of lamin B in prostate cancer strongly correlate with tumor differentiation (31); in skin cancer, absent to low levels of lamin A correlate with rapid growth in basal cell carcinoma (189). Similarly, lamin A/C silencing has been documented in leukemias and lymphomas (2). In addition to variations in protein expression levels, the intranuclear distribution of these proteins might also change. In metastatic breast cancer cells, lamins A and C are more tightly associated with DNA than in non-invasive cells, suggesting re-arrangements of nuclear lamins (173). Since lamins play a critical role in DNA and RNA synthesis and processing $(103,172,180)$, these changes could result in altered gene expression that drives further changes. As described above in the paragraph on nuclear mechanics in stem cells, reduced lamin A/C expression corresponds to a less differentiated cell state and results in reduced nuclear stiffness (105). Such changes in nuclear stiffness can serve as an indicator for increased motility of tumor cells and metastatic potential $(200,201)$ and might facilitate migration of metastatic cells through small tissue spaces. As loss of lamin A/C can also cause increased cellular sensitivity to mechanical stress and impaired mechanotransduction signaling (107) and breast epithelial cells rely on intrinsic feedback between their physical environment and their cytoskeletal tension (149), changes in mechanotransduction signaling could have direct consequences on tumorigenesis and metastatic potential. It will thus be interesting to explore the role of altered nuclear structure and mechanics on cancer progression in future studies.

\section{Conclusion}

Over the last decade, we have made great strides toward improving our understanding of nuclear mechanics and its relevance to cellular function. Stimulated by the many diseases linked to nuclear envelope proteins, we have come to realize that the nucleus and the nuclear envelope are not merely passive mechanical structures that separate the genetic content from the cytoplasm. While the nuclear envelope does provide vital protection to the nucleus, particularly in mechanically stressed tissues such as muscle, it can, through an ever growing number of identified interactions between nuclear envelope proteins and transcriptional regulators, also act as a signaling filter, sequestering proteins at the nuclear envelope or regulating their degradation. Furthermore, the nuclear envelope and structural proteins within the nuclear interior emerge to play important roles in the organization of the genetic content. Following the completion of the human genome project, which provided the linear sequence of the genetic information, much research is now focused on elucidating the 3dimensional configuration of the genome and how the spatial organization can modulate transcriptional activity. The nuclear envelope (and the nuclear matrix) plays an important role in this 3-D puzzle, as changes in lamin expression have dramatic consequences on chromatin structure. These modifications do not only affect the transcriptional plasticity of the nucleus, but also its physical stiffness, which can be directly quantified by micropipette aspiration or similar techniques. Importantly, we now have to recognize that structural changes in the nucleus can have direct consequences beyond the nucleus itself, as they can result in defective nuclear cytoskeletal coupling, altered centrosome positioning, and defects in cytoskeletal organization and stiffness, thereby affecting cellular functions such as polarization and migration. 
While much progress has been made in understanding the physical behavior of the nucleus under applied forces and identifying the contribution of specific proteins to this behavior, many unsolved problems remain at hand. Regarding the mechanics itself, we still know very little on the relative contribution between the nuclear envelope and the nuclear interior in somatic cells. Furthermore, neither the exact molecular structure of the molecular lamina nor the nature of the intranuclear lamin network have been sufficiently resolved for somatic cells, making it difficult to assess the effect of specific disease-causing mutations. This applies even more to the incomplete list of the various interactions that these proteins can have with transcription factors and other nuclear (and cytoskeletal) proteins. Lacking this knowledge, it remains a challenge to interpret the various defects associated with mutations in nuclear envelope proteins or the effect of physiological modulations of expression levels as seen during stem cell differentiation or in diverse cell types. Lastly, the question of how changes in nuclear morphology observed in many cancers relate to the malicious functions in these cells remains another intriguing problem with important consequences.

To address these questions, we will require multi-disciplinary and multi-scale approaches to unravel the complex structural-functional relationships found in the nucleus and the cell itself. Close collaborations between biophysicists, engineers, and molecular, cell, and structural biologists will be imperative to achieve these goals, as is the combination of in vitro studies on simple experimental systems, experiments on intact cells resembling physiological conditions, and investigation of live organisms, ranging from C. elegans to mice. These studies, while arduous and challenging, will tremendously benefit from rapidly advancing research in super-resolution imaging that is becoming suitable for live cells, the continuous development of novel experimental techniques to probe cellular and sub-cellular biomechanics, and the increasing application of high throughput techniques to study large numbers of cells and conditions. As a consequence, the coming years promise to further improve our insights into the functional relevance of nuclear structure and mechanics, with the ultimate goal of providing new means and targets for therapeutic interventions in human diseases as varied as cancer, premature aging, and cardiovascular disease.

\section{Acknowledgments}

This work was supported by National Institutes of Health grants HL082792 and NS059348 and the American Heart Association grant $0635359 \mathrm{~N}$

\section{References}

1. Aebi U, Cohn J, Buhle L, Gerace L. The nuclear lamina is a meshwork of intermediate-type filaments. Nature. 1986; 323:560-564. [PubMed: 3762708]

2. Agrelo R, Setien F, Espada J, Artiga MJ, Rodriguez M, Perez-Rosado A, Sanchez-Aguilera A, Fraga MF, Piris MA, Esteller M. Inactivation of the lamin A/C gene by $\mathrm{CpG}$ island promoter hypermethylation in hematologic malignancies, and its association with poor survival in nodal diffuse large B-cell lymphoma. J Clin Oncol. 2005; 23:3940-3947. [PubMed: 15867203]

3. Al-Shali KZ, Hegele RA. Laminopathies and atherosclerosis. Arterioscler Thromb Vasc Biol. 2004; 24:1591-1595. [PubMed: 15205220]

4. Apel ED, Lewis RM, Grady RM, Sanes JR. Syne-1, a dystrophin- and Klarsicht-related protein associated with synaptic nuclei at the neuromuscular junction. J Biol Chem. 2000; 275:3198631995. [PubMed: 10878022] 
5. Bakay M, Wang Z, Melcon G, Schiltz L, Xuan J, Zhao P, Sartorelli V, Seo J, Pegoraro E, Angelini C, Shneiderman B, Escolar D, Chen YW, Winokur ST, Pachman LM, Fan C, Mandler R, Nevo Y, Gordon E, Zhu Y, Dong Y, Wang Y, Hoffman EP. Nuclear envelope dystrophies show a transcriptional fingerprint suggesting disruption of Rb-MyoD pathways in muscle regeneration. Brain. 2006

6. Baker PB, Baba N, Boesel CP. Cardiovascular abnormalities in progeria. Case report and review of the literature. Arch Pathol Lab Med. 1981; 105:384-386. [PubMed: 6894691]

7. Bengtsson L, Wilson KL. Multiple and surprising new functions for emerin, a nuclear membrane protein. Curr Opin Cell Biol. 2004; 16:73-79. [PubMed: 15037308]

8. Bettinger BT, Gilbert DM, Amberg DC. Actin up in the nucleus. Nat Rev Mol Cell Biol. 2004; 5:410-415. [PubMed: 15122354]

9. Bhattacharya D, Talwar S, Mazumder A, Shivashankar GV. Spatio-temporal plasticity in chromatin organization in mouse cell differentiation and during Drosophila embryogenesis. Biophys J. 2009; 96:3832-3839. [PubMed: 19413989]

10. Bibikova M, Laurent LC, Ren B, Loring JF, Fan JB. Unraveling epigenetic regulation in embryonic stem cells. Cell Stem Cell. 2008; 2:123-134. [PubMed: 18371433]

11. Bione S, Maestrini E, Rivella S, Mancini M, Regis S, Romeo G, Toniolo D. Identification of a novel X-linked gene responsible for Emery-Dreifuss muscular dystrophy. Nat Genet. 1994; 8:323327. [PubMed: 7894480]

12. Bissell MJ, Weaver VM, Lelièvre SA, Wang F, Petersen OW, Schmeichel KL. Tissue structure, nuclear organization, and gene expression in normal and malignant breast. Cancer Res. 1999; 59:1757-1763. [PubMed: 10197593]

13. Blau HM, Pavlath GK, Hardeman EC, Chiu CP, Silberstein L, Webster SG, Miller SC, Webster C. Plasticity of the differentiated state. Science. 1985; 230:758-766. [PubMed: 2414846]

14. Boccardo F, Rubagotti A, Carmignani G, Romagnoli A, Nicolo G, Barboro P, Parodi S, Patrone E, Balbi C. Nuclear matrix proteins changes in cancerous prostate tissues and their prognostic value in clinically localized prostate cancer. Prostate. 2003; 55:259-264. [PubMed: 12712405]

15. Bonne G, Di Barletta MR, Varnous S, Becane HM, Hammouda EH, Merlini L, Muntoni F, Greenberg CR, Gary F, Urtizberea JA, Duboc D, Fardeau M, Toniolo D, Schwartz K. Mutations in the gene encoding lamin A/C cause autosomal dominant Emery-Dreifuss muscular dystrophy. Nat Genet. 1999; 21:285-288. [PubMed: 10080180]

16. Brodsky GL, Muntoni F, Miocic S, Sinagra G, Sewry C, Mestroni L. Lamin A/C gene mutation associated with dilated cardiomyopathy with variable skeletal muscle involvement. Circulation. 2000; 101:473-476. [PubMed: 10662742]

17. Broers JL, Bronnenberg NM, Kuijpers HJ, Schutte B, Hutchison CJ, Ramaekers FC. Partial cleavage of A-type lamins concurs with their total disintegration from the nuclear lamina during apoptosis. Eur J Cell Biol. 2002; 81:677-691. [PubMed: 12553668]

18. Broers JL, Hutchison CJ, Ramaekers FC. Laminopathies. J Pathol. 2004; 204:478-488. [PubMed: 15495262]

19. Broers JL, Peeters EA, Kuijpers HJ, Endert J, Bouten CV, Oomens CW, Baaijens FP, Ramaekers FC. Decreased mechanical stiffness in LMNA-/- cells is caused by defective nucleo-cytoskeletal integrity: implications for the development of laminopathies. Hum Mol Genet. 2004; 13:25672580. [PubMed: 15367494]

20. Broers JLV, Kuijpers HJH, Ostlund C, Worman HJ, Endert J, Ramaekers FCS. Both lamin A and lamin $\mathrm{C}$ mutations cause lamina instability as well as loss of internal nuclear lamin organization. Exp Cell Res. 2005; 304:582-592. [PubMed: 15748902]

21. Burke B, Roux KJ. Nuclei take a position: managing nuclear location. Dev Cell. 2009; 17:587597. [PubMed: 19922864]

22. Burke B, Stewart CL. Life at the edge: the nuclear envelope and human disease. Nat Rev Mol Cell Biol. 2002; 3:575-585. [PubMed: 12154369]

23. Bussolati G, Marchio C, Gaetano L, Lupo R, Sapino A. Pleomorphism of the nuclear envelope in breast cancer: a new approach to an old problem. J Cell Mol Med. 2008; 12:209-218. [PubMed: 18053086] 
24. Caille N, Tardy Y, Meister JJ. Assessment of strain field in endothelial cells subjected to uniaxial deformation of their substrate. Ann Biomed Eng. 1998; 26:409-416. [PubMed: 9570224]

25. Caille N, Thoumine O, Tardy Y, Meister JJ. Contribution of the nucleus to the mechanical properties of endothelial cells. J Biomech. 2002; 35:177-187. [PubMed: 11784536]

26. Cao H, Hegele RA. Nuclear lamin A/C R482Q mutation in canadian kindreds with Dunnigan-type familial partial lipodystrophy. Hum Mol Genet. 2000; 9:109-112. [PubMed: 10587585]

27. Cenni V, Sabatelli P, Mattioli E, Marmiroli S, Capanni C, Ognibene A, Squarzoni S, Maraldi NM, Bonne G, Columbaro M, Merlini L, Lattanzi G. Lamin A N-terminal phosphorylation is associated with myoblast activation: impairment in Emery-Dreifuss muscular dystrophy. J Med Genet. 2005; 42:214-220. [PubMed: 15744034]

28. Chen L, Lee L, Kudlow BA, Dos Santos HG, Sletvold O, Shafeghati Y, Botha EG, Garg A, Hanson NB, Martin GM, Mian IS, Kennedy BK, Oshima J. LMNA mutations in atypical Werner's syndrome. Lancet. 2003; 362:440-445. [PubMed: 12927431]

29. Coffinier C, Chang SY, Nobumori C, Tu Y, Farber EA, Toth JI, Fong LG, Young SG. Abnormal development of the cerebral cortex and cerebellum in the setting of lamin B2 deficiency. Proc Natl Acad Sci U S A. 2010; 107:5076-5081. [PubMed: 20145110]

30. Constantinescu D, Gray HL, Sammak PJ, Schatten GP, Csoka AB. Lamin A/C expression is a marker of mouse and human embryonic stem cell differentiation. Stem Cells. 2006; 24:177-185. [PubMed: 16179429]

31. Coradeghini R, Barboro P, Rubagotti A, Boccardo F, Parodi S, Carmignani G, D'Arrigo C, Patrone E, Balbi C. Differential expression of nuclear lamins in normal and cancerous prostate tissues. Oncol Rep. 2006; 15:609-613. [PubMed: 16465420]

32. Corso C, Parry EM, Faragher RG, Seager A, Green MH, Parry JM. Molecular cytogenetic insights into the ageing syndrome Hutchinson-Gilford Progeria (HGPS). Cytogenet Genome Res. 2005; 111:27-33. [PubMed: 16093717]

33. Crisp M, Liu Q, Roux K, Rattner JB, Shanahan C, Burke B, Stahl PD, Hodzic D. Coupling of the nucleus and cytoplasm: role of the LINC complex. J Cell Biol. 2006; 172:41-53. [PubMed: 16380439]

34. Csoka AB, English SB, Simkevich CP, Ginzinger DG, Butte AJ, Schatten GP, Rothman FG, Sedivy JM. Genome-scale expression profiling of Hutchinson-Gilford progeria syndrome reveals widespread transcriptional misregulation leading to mesodermal/mesenchymal defects and accelerated atherosclerosis. Aging Cell. 2004; 3:235-243. [PubMed: 15268757]

35. Cupesi M, Yoshioka J, Gannon J, Kudinova A, Stewart CL, Lammerding J. Attenuated hypertrophic response to pressure overload in a lamin A/C haploinsufficiency mouse. J Mol Cell Cardiol. 2009

36. Dahl KN, Engler AJ, Pajerowski JD, Discher DE. Power-law rheology of isolated nuclei with deformation mapping of nuclear substructures. Biophys J. 2005; 89:2855-2864. [PubMed: 16055543]

37. Dahl KN, Kahn SM, Wilson KL, Discher DE. The nuclear envelope lamina network has elasticity and a compressibility limit suggestive of a molecular shock absorber. J Cell Sci. 2004; 117:47794786. [PubMed: 15331638]

38. Dahl KN, Kalinowski A, Pekkan K. Mechanobiology and the microcirculation: cellular, nuclear and fluid mechanics. Microcirculation. 2010; 17:179-191. [PubMed: 20374482]

39. Dahl KN, Ribeiro AJ, Lammerding J. Nuclear shape, mechanics, and mechanotransduction. Circ Res. 2008; 102:1307-1318. [PubMed: 18535268]

40. Dahl KN, Scaffidi P, Islam MF, Yodh AG, Wilson KL, Misteli T. Distinct structural and mechanical properties of the nuclear lamina in Hutchinson-Gilford progeria syndrome. Proc Natl Acad Sci U S A. 2006; 103:10271-10276. [PubMed: 16801550]

41. Davies PF. Flow-mediated endothelial mechanotransduction. Physiol Rev. 1995; 75:519-560. [PubMed: 7624393]

42. De Sandre-Giovannoli A, Bernard R, Cau P, Navarro C, Amiel J, Boccaccio I, Lyonnet S, Stewart CL, Munnich A, Le Merrer M, Levy N. Lamin A Truncation in Hutchinson-Gilford Progeria. Science. 2003; 300:2055. [PubMed: 12702809] 
43. De Sandre-Giovannoli A, Chaouch M, Kozlov S, Vallat JM, Tazir M, Kassouri N, Szepetowski P, Hammadouche T, Vandenberghe A, Stewart CL, Grid D, Levy N. Homozygous defects in LMNA, encoding lamin A/C nuclear-envelope proteins, cause autosomal recessive axonal neuropathy in human (Charcot-Marie-Tooth disorder type 2) and mouse. Am J Hum Genet. 2002; 70:726-736. [PubMed: 11799477]

44. de Vries AH, Krenn BE, van Driel R, Subramaniam V, Kanger JS. Direct observation of nanomechanical properties of chromatin in living cells. Nano Lett. 2007; 7:1424-1427. [PubMed: 17451276]

45. Dechat T, Pfleghaar K, Sengupta K, Shimi T, Shumaker DK, Solimando L, Goldman RD. Nuclear lamins: major factors in the structural organization and function of the nucleus and chromatin. Genes Dev. 2008; 22:832-853. [PubMed: 18381888]

46. Deguchi S, Maeda K, Ohashi T, Sato M. Flow-induced hardening of endothelial nucleus as an intracellular stress-bearing organelle. J Biomech. 2005; 38:1751-1759. [PubMed: 16005465]

47. Delbarre E, Tramier M, Coppey-Moisan M, Gaillard C, Courvalin JC, Buendia B. The truncated prelamin A in Hutchinson-Gilford progeria syndrome alters segregation of A-type and B-type lamin homopolymers. Hum Mol Genet. 2006; 15:1113-1122. [PubMed: 16481358]

48. Ding X, Xu R, Yu J, Xu T, Zhuang Y, Han M. SUN1 is required for telomere attachment to nuclear envelope and gametogenesis in mice. Dev Cell. 2007; 12:863-872. [PubMed: 17543860]

49. Dreuillet C, Tillit J, Kress M, Ernoult-Lange M. In vivo and in vitro interaction between human transcription factor MOK2 and nuclear lamin A/C. Nucleic Acids Res. 2002; 30:4634-4642. [PubMed: 12409453]

50. Engler AJ, Sen S, Sweeney HL, Discher DE. Matrix elasticity directs stem cell lineage specification. Cell. 2006; 126:677-689. [PubMed: 16923388]

51. Eriksson M, Brown WT, Gordon LB, Glynn MW, Singer J, Scott L, Erdos MR, Robbins CM, Moses TY, Berglund P, Dutra A, Pak E, Durkin S, Csoka AB, Boehnke M, Glover TW, Collins FS. Recurrent de novo point mutations in lamin A cause Hutchinson-Gilford progeria syndrome. Nature. 2003; 423:293-298. [PubMed: 12714972]

52. Fan J, Beck KA. A role for the spectrin superfamily member Syne-1 and kinesin II in cytokinesis. J Cell Sci. 2004; 117:619-629. [PubMed: 14709720]

53. Fatkin D, MacRae C, Sasaki T, Wolff MR, Porcu M, Frenneaux M, Atherton J, Vidaillet HJ Jr, Spudich S, De Girolami U, Seidman JG, Seidman C, Muntoni F, Muehle G, Johnson W, McDonough B. Missense mutations in the rod domain of the lamin A/C gene as causes of dilated cardiomyopathy and conduction-system disease. N Engl J Med. 1999; 341:1715-1724. [PubMed: 10580070]

54. Favreau C, Higuet D, Courvalin JC, Buendia B. Expression of a mutant lamin A that causes Emery-Dreifuss muscular dystrophy inhibits in vitro differentiation of $\mathrm{C} 2 \mathrm{C} 12$ myoblasts. Mol Cell Biol. 2004; 24:1481-1492. [PubMed: 14749366]

55. Fidzianska A, Hausmanowa-Petrusewicz I. Architectural abnormalities in muscle nuclei. Ultrastructural differences between X-linked and autosomal dominant forms of EDMD. J Neurol Sci. 2003; 210:47-51. [PubMed: 12736087]

56. Fidzianska A, Toniolo D, Hausmanowa-Petrusewicz I. Ultrastructural abnormality of sarcolemmal nuclei in Emery-Dreifuss muscular dystrophy (EDMD). J Neurol Sci. 1998; 159:88-93. [PubMed: 9700709]

57. Frock RL, Kudlow BA, Evans AM, Jameson SA, Hauschka SD, Kennedy BK. Lamin A/C and emerin are critical for skeletal muscle satellite cell differentiation. Genes Dev. 2006; 20:486-500. [PubMed: 16481476]

58. Gieni RS, Hendzel MJ. Actin dynamics and functions in the interphase nucleus: moving toward an understanding of nuclear polymeric actin. Biochem Cell Biol. 2009; 87:283-306. [PubMed: 19234542]

59. Gilchrist CL, Witvoet-Braam SW, Guilak F, Setton LA. Measurement of intracellular strain on deformable substrates with texture correlation. J Biomech. 2007; 40:786-794. [PubMed: 16698026]

60. Goldberg MW, Fiserova J, Huttenlauch I, Stick R. A new model for nuclear lamina organization. Biochem Soc Trans. 2008; 36:1339-1343. [PubMed: 19021552] 
61. Goldberg MW, Huttenlauch I, Hutchison CJ, Stick R. Filaments made from A- and B-type lamins differ in structure and organization. J Cell Sci. 2008; 121:215-225. [PubMed: 18187453]

62. Gonzalez JM, Navarro-Puche A, Casar B, Crespo P, Andres V. Fast regulation of AP-1 activity through interaction of lamin A/C, ERK1/2, and c-Fos at the nuclear envelope. J Cell Biol. 2008; 183:653-666. [PubMed: 19015316]

63. Gotic I, Schmidt WM, Biadasiewicz K, Leschnik M, Spilka R, Braun J, Stewart CL, Foisner R. Loss of LAP2 alpha delays satellite cell differentiation and affects postnatal fiber-type determination. Stem Cells. 2010; 28:480-488. [PubMed: 20039368]

64. Grady RM, Starr DA, Ackerman GL, Sanes JR, Han M. Syne proteins anchor muscle nuclei at the neuromuscular junction. Proc Natl Acad Sci U S A. 2005; 102:4359-4364. [PubMed: 15749817]

65. Gros-Louis F, Dupre N, Dion P, Fox MA, Laurent S, Verreault S, Sanes JR, Bouchard JP, Rouleau GA. Mutations in SYNE1 lead to a newly discovered form of autosomal recessive cerebellar ataxia. Nat Genet. 2007; 39:80-85. [PubMed: 17159980]

66. Guilak F. Compression-induced changes in the shape and volume of the chondrocyte nucleus. J Biomech. 1995; 28:1529-1541. [PubMed: 8666592]

67. Guilak F, Tedrow JR, Burgkart R. Viscoelastic properties of the cell nucleus. Biochem Biophys Res Commun. 2000; 269:781-786. [PubMed: 10720492]

68. Hahn C, Schwartz MA. Mechanotransduction in vascular physiology and atherogenesis. Nat Rev Mol Cell Biol. 2009; 10:53-62. [PubMed: 19197332]

69. Hale CM, Shrestha AL, Khatau SB, Stewart-Hutchinson PJ, Hernandez L, Stewart CL, Hodzic D, Wirtz D. Dysfunctional connections between the nucleus and the actin and microtubule networks in laminopathic models. Biophys J. 2008; 95:5462-5475. [PubMed: 18790843]

70. Haque F, Lloyd DJ, Smallwood DT, Dent CL, Shanahan CM, Fry AM, Trembath RC, Shackleton S. SUN1 interacts with nuclear lamin A and cytoplasmic nesprins to provide a physical connection between the nuclear lamina and the cytoskeleton. Mol Cell Biol. 2006; 26:3738-3751. [PubMed: 16648470]

71. Haque F, Mazzeo D, Patel JT, Smallwood DT, Ellis JA, Shanahan CM, Shackleton S. Mammalian SUN protein interaction networks at the inner nuclear membrane and their role in laminopathy disease processes. J Biol Chem. 2010; 285:3487-3498. [PubMed: 19933576]

72. Haraguchi T, Holaska JM, Yamane M, Koujin T, Hashiguchi N, Mori C, Wilson KL, Hiraoka Y. Emerin binding to Btf, a death-promoting transcriptional repressor, is disrupted by a missense mutation that causes Emery-Dreifuss muscular dystrophy. Eur J Biochem. 2004; 271:1035-1045. [PubMed: 15009215]

73. Haraguchi T, Koujin T, Segura-Totten M, Lee KK, Matsuoka Y, Yoneda Y, Wilson KL, Hiraoka Y. BAF is required for emerin assembly into the reforming nuclear envelope. J Cell Sci. 2001; 114:4575-4585. [PubMed: 11792822]

74. Harborth J, Elbashir SM, Bechert K, Tuschl T, Weber K. Identification of essential genes in cultured mammalian cells using small interfering RNAs. J Cell Sci. 2001; 114:4557-4565. [PubMed: 11792820]

75. Hasan S, Guttinger S, Muhlhausser P, Anderegg F, Burgler S, Kutay U. Nuclear envelope localization of human UNC84A does not require nuclear lamins. FEBS Lett. 2006; 580:12631268. [PubMed: 16445915]

76. Hazel AL, Pedley TJ. Vascular endothelial cells minimize the total force on their nuclei. Biophys J. 2000; 78:47-54. [PubMed: 10620272]

77. Hegele RA, Cao H, Liu DM, Costain GA, Charlton-Menys V, Rodger NW, Durrington PN. Sequencing of the reannotated LMNB2 gene reveals novel mutations in patients with acquired partial lipodystrophy. Am J Hum Genet. 2006; 79:383-389. [PubMed: 16826530]

78. Hodzic DM, Yeater DB, Bengtsson L, Otto H, Stahl PD. Sun2 is a novel mammalian inner nuclear membrane protein. J Biol Chem. 2004; 279:25805-25812. [PubMed: 15082709]

79. Hoffman RM. Real-time subcellular imaging in live animals: new visible targets for cancer drug discovery. IDrugs. 2006; 9:632-635. [PubMed: 16952071]

80. Hoffmann K, Dreger CK, Olins AL, Olins DE, Shultz LD, Lucke B, Karl H, Kaps R, Muller D, Vaya A, Aznar J, Ware RE, Sotelo Cruz N, Lindner TH, Herrmann H, Reis A, Sperling K. 
Mutations in the gene encoding the lamin B receptor produce an altered nuclear morphology in granulocytes (Pelger-Huet anomaly). Nat Genet. 2002; 31:410-414. [PubMed: 12118250]

81. Hoffmann K, Sperling K, Olins AL, Olins DE. The granulocyte nucleus and lamin B receptor: avoiding the ovoid. Chromosoma. 2007; 116:227-235. [PubMed: 17245605]

82. Hoffmann K, Sperling K, Olins AL, Olins DE. The granulocyte nucleus and lamin B receptor: avoiding the ovoid. Chromosoma. 2007; 116:227-235. [PubMed: 17245605]

83. Hofmann WA, Johnson T, Klapczynski M, Fan JL, Lanerolle P. From transcription to transport: emerging roles for nuclear myosin I. Biochem Cell Biol. 2006; 84:418-426. [PubMed: 16936815]

84. Holaska JM. Emerin and the nuclear lamina in muscle and cardiac disease. Circ Res. 2008; 103:16-23. [PubMed: 18596264]

85. Holaska JM, Kowalski AK, Wilson KL. Emerin caps the pointed end of actin filaments: evidence for an actin cortical network at the nuclear inner membrane. PLoS Biol. 2004; 2:E231. [PubMed: 15328537]

86. Holaska JM, Lee KK, Kowalski AK, Wilson KL. Transcriptional repressor germ cell-less (GCL) and barrier to autointegration factor (BAF) compete for binding to emerin in vitro. J Biol Chem. 2003; 278:6969-6975. [PubMed: 12493765]

87. Holaska JM, Wilson KL. An emerin "proteome": purification of distinct emerin-containing complexes from HeLa cells suggests molecular basis for diverse roles including gene regulation, mRNA splicing, signaling, mechanosensing, and nuclear architecture. Biochemistry. 2007; 46:8897-8908. [PubMed: 17620012]

88. Hoshiba T, Yamada T, Lu H, Kawazoe N, Tateishi T, Chen G. Nuclear deformation and expression change of cartilaginous genes during in vitro expansion of chondrocytes. Biochem Biophys Res Commun. 2008; 374:688-692. [PubMed: 18675249]

89. Houben F, Willems CH, Declercq IL, Hochstenbach K, Kamps MA, Snoeckx LH, Ramaekers FC, Broers JL. Disturbed nuclear orientation and cellular migration in A-type lamin deficient cells. Biochim Biophys Acta. 2009; 1793:312-324. [PubMed: 19013199]

90. Hu S, Chen J, Butler JP, Wang N. Prestress mediates force propagation into the nucleus. Biochem Biophys Res Commun. 2005; 329:423-428. [PubMed: 15737604]

91. Hudson ME, Pozdnyakova I, Haines K, Mor G, Snyder M. Identification of differentially expressed proteins in ovarian cancer using high-density protein microarrays. Proc Natl Acad Sci U S A. 2007; 104:17494-17499. [PubMed: 17954908]

92. Hutchison CJ. Lamins: building blocks or regulators of gene expression? Nat Rev Mol Cell Biol. 2002; 3:848-858. [PubMed: 12415302]

93. Hutchison CJ, Worman HJ. A-type lamins: guardians of the soma? Nat Cell Biol. 2004; 6:10621067. [PubMed: 15517000]

94. Jean RP, Gray DS, Spector AA, Chen CS. Characterization of the nuclear deformation caused by changes in endothelial cell shape. J Biomech Eng. 2004; 126:552-558. [PubMed: 15648807]

95. Ji JY, Lee RT, Vergnes L, Fong LG, Stewart CL, Reue K, Young SG, Zhang Q, Shanahan CM, Lammerding J. Cell nuclei spin in the absence of lamin b1. J Biol Chem. 2007; 282:20015-20026. [PubMed: 17488709]

96. Jockusch BM, Schoenenberger CA, Stetefeld J, Aebi U. Tracking down the different forms of nuclear actin. Trends Cell Biol. 2006; 16:391-396. [PubMed: 16828286]

97. Johnson BR, Nitta RT, Frock RL, Mounkes L, Barbie DA, Stewart CL, Harlow E, Kennedy BK. A-type lamins regulate retinoblastoma protein function by promoting subnuclear localization and preventing proteasomal degradation. Proc Natl Acad Sci U S A. 2004; 101:9677-9682. [PubMed: 15210943]

98. Kha HN, Chen BK, Clark GM, Jones R. Stiffness properties for Nucleus standard straight and contour electrode arrays. Med Eng Phys. 2004; 26:677-685. [PubMed: 15471696]

99. Khatau SB, Hale CM, Stewart-Hutchinson PJ, Patel MS, Stewart CL, Searson PC, Hodzic D, Wirtz D. A perinuclear actin cap regulates nuclear shape. Proc Natl Acad Sci U S A. 2009; 106:1901719022. [PubMed: 19850871]

100. Kirschner J, Brune T, Wehnert M, Denecke J, Wasner C, Feuer A, Marquardt T, Ketelsen UP, Wieacker P, Bonnemann CG, Korinthenberg R. p.S143F mutation in lamin A/C: A new 
phenotype combining myopathy and progeria. Ann Neurol. 2005; 57:148-151. [PubMed: 15622532]

101. Kiseleva E, Drummond SP, Goldberg MW, Rutherford SA, Allen TD, Wilson KL. Actin- and protein-4.1-containing filaments link nuclear pore complexes to subnuclear organelles in Xenopus oocyte nuclei. J Cell Sci. 2004; 117:2481-2490. [PubMed: 15128868]

102. Krauss SW, Chen C, Penman S, Heald R. Nuclear actin and protein 4.1: essential interactions during nuclear assembly in vitro. Proc Natl Acad Sci U S A. 2003; 100:10752-10757. [PubMed: 12960380]

103. Kumaran RI, Muralikrishna B, Parnaik VK. Lamin A/C speckles mediate spatial organization of splicing factor compartments and RNA polymerase II transcription. J Cell Biol. 2002; 159:783793. [PubMed: 12473687]

104. Lammerding J, Dahl KN, Discher DE, Kamm RD. Nuclear mechanics and methods. Methods Cell Biol. 2007; 83:269-294. [PubMed: 17613312]

105. Lammerding J, Fong LG, Ji JY, Reue K, Stewart CL, Young SG, Lee RT. Lamins A and C but not lamin B1 regulate nuclear mechanics. J Biol Chem. 2006; 281:25768-25780. [PubMed: 16825190]

106. Lammerding J, Hsiao J, Schulze PC, Kozlov S, Stewart CL, Lee RT. Abnormal nuclear shape and impaired mechanotransduction in emerin-deficient cells. J Cell Biol. 2005; 170:781-791. [PubMed: 16115958]

107. Lammerding J, Schulze PC, Takahashi T, Kozlov S, Sullivan T, Kamm RD, Stewart CL, Lee RT. Lamin A/C Deficiency Causes Defective Nuclear Mechanics and Mechanotransduction. J Clin Invest. 2004; 113:370-378. [PubMed: 14755334]

108. Langevin HM, Bouffard NA, Badger GJ, Churchill DL, Howe AK. Subcutaneous tissue fibroblast cytoskeletal remodeling induced by acupuncture: evidence for a mechanotransduction-based mechanism. J Cell Physiol. 2006; 207:767-774. [PubMed: 16511830]

109. Langevin HM, Bouffard NA, Badger GJ, Iatridis JC, Howe AK. Dynamic fibroblast cytoskeletal response to subcutaneous tissue stretch ex vivo and in vivo. Am J Physiol Cell Physiol. 2005; 288:C747-756. [PubMed: 15496476]

110. Lee DA, Knight MM, Bolton JF, Idowu BD, Kayser MV, Bader DL. Chondrocyte deformation within compressed agarose constructs at the cellular and sub-cellular levels. J Biomech. 2000; 33:81-95. [PubMed: 10609521]

111. Lee JS, Hale CM, Panorchan P, Khatau SB, George JP, Tseng Y, Stewart CL, Hodzic D, Wirtz D. Nuclear lamin A/C deficiency induces defects in cell mechanics, polarization, and migration. Biophys J. 2007; 93:2542-2552. [PubMed: 17631533]

112. Lee JS, Hale CM, Panorchan P, Khatau SB, George JP, Tseng Y, Stewart CL, Hodzic D, Wirtz D. Nuclear lamin A/C deficiency induces defects in cell mechanics, polarization, and migration. Biophys J. 2007; 93:2542-2552. [PubMed: 17631533]

113. Lelièvre SA, Weaver VM, Nickerson JA, Larabell CA, Bhaumik A, Petersen OW, Bissell MJ. Tissue phenotype depends on reciprocal interactions between the extracellular matrix and the structural organization of the nucleus. Proc Natl Acad Sci U S A. 1998; 95:14711-14716. [PubMed: 9843954]

114. Leman ES, Getzenberg RH. Nuclear matrix proteins as biomarkers in prostate cancer. J Cell Biochem. 2002; 86:213-223. [PubMed: 12111991]

115. Libotte T, Zaim H, Abraham S, Padmakumar VC, Schneider M, Lu W, Munck M, Hutchison C, Wehnert M, Fahrenkrog B, Sauder U, Aebi U, Noegel AA, Karakesisoglou I. Lamin A/Cdependent localization of Nesprin-2, a giant scaffolder at the nuclear envelope. Mol Biol Cell. 2005; 16:3411-3424. [PubMed: 15843432]

116. Lieberman-Aiden E, van Berkum NL, Williams L, Imakaev M, Ragoczy T, Telling A, Amit I, Lajoie BR, Sabo PJ, Dorschner MO, Sandstrom R, Bernstein B, Bender MA, Groudine M, Gnirke A, Stamatoyannopoulos J, Mirny LA, Lander ES, Dekker J. Comprehensive mapping of long-range interactions reveals folding principles of the human genome. Science. 2009; 326:289293. [PubMed: 19815776]

117. Liu B, Wang J, Chan KM, Tjia WM, Deng W, Guan X, Huang JD, Li KM, Chau PY, Chen DJ, Pei D, Pendas AM, Cadinanos J, Lopez-Otin C, Tse HF, Hutchison C, Chen J, Cao Y, Cheah KS, 
Tryggvason K, Zhou Z. Genomic instability in laminopathy-based premature aging. Nat Med. 2005; 11:780-785. [PubMed: 15980864]

118. Liu Q, Pante N, Misteli T, Elsagga M, Crisp M, Hodzic D, Burke B, Roux KJ. Functional association of Sun1 with nuclear pore complexes. J Cell Biol. 2007; 178:785-798. [PubMed: 17724119]

119. Lloyd DJ, Trembath RC, Shackleton S. A novel interaction between lamin A and SREBP1: implications for partial lipodystrophy and other laminopathies. Hum Mol Genet. 2002; 11:769 777. [PubMed: 11929849]

120. Maniotis AJ, Chen CS, Ingber DE. Demonstration of mechanical connections between integrins, cytoskeletal filaments, and nucleoplasm that stabilize nuclear structure. Proc Natl Acad Sci U S A. 1997; 94:849-854. [PubMed: 9023345]

121. Markiewicz E, Ledran M, Hutchison CJ. Remodelling of the nuclear lamina and nucleoskeleton is required for skeletal muscle differentiation in vitro. J Cell Sci. 2005; 118:409-420. [PubMed: 15654018]

122. Mathur AB, Reichert WM, Truskey GA. Flow and high affinity binding affect the elastic modulus of the nucleus, cell body and the stress fibers of endothelial cells. Ann Biomed Eng. 2007; 35:1120-1130. [PubMed: 17385045]

123. Meaburn KJ, Misteli T. Cell biology: chromosome territories. Nature. 2007; 445:379-781. [PubMed: 17251970]

124. Mejat A, Decostre V, Li J, Renou L, Kesari A, Hantai D, Stewart CL, Xiao X, Hoffman E, Bonne G, Misteli T. Lamin A/C-mediated neuromuscular junction defects in Emery-Dreifuss muscular dystrophy. J Cell Biol. 2009; 184:31-44. [PubMed: 19124654]

125. Melcon G, Kozlov S, Cutler DA, Sullivan T, Hernandez L, Zhao P, Mitchell S, Nader G, Bakay M, Rottman JN, Hoffman EP, Stewart CL. Loss of emerin at the nuclear envelope disrupts the Rb1/E2F and MyoD pathways during muscle regeneration. Hum Mol Genet. 2006; 15:637-651. [PubMed: 16403804]

126. Meshorer E, Gruenbaum Y. Gone with the Wnt/Notch: stem cells in laminopathies, progeria, and aging. J Cell Biol. 2008; 181:9-13. [PubMed: 18378774]

127. Meshorer E, Yellajoshula D, George E, Scambler PJ, Brown DT, Misteli T. Hyperdynamic plasticity of chromatin proteins in pluripotent embryonic stem cells. Dev Cell. 2006; 10:105-116. [PubMed: 16399082]

128. Mislow JM, Holaska JM, Kim MS, Lee KK, Segura-Totten M, Wilson KL, McNally EM. Nesprin-1alpha self-associates and binds directly to emerin and lamin A in vitro. FEBS Lett. 2002; 525:135-140. [PubMed: 12163176]

129. Moir RD, Yoon M, Khuon S, Goldman RD. Nuclear lamins A and B1: different pathways of assembly during nuclear envelope formation in living cells. J Cell Biol. 2000; 151:1155-1168. [PubMed: 11121432]

130. Mounkes LC, Stewart CL. Aging and nuclear organization: lamins and progeria. Curr Opin Cell Biol. 2004; 16:322-327. [PubMed: 15145358]

131. Muchir A, Bonne G, van der Kooi AJ, van Meegen M, Baas F, Bolhuis PA, de Visser M, Schwartz K. Identification of mutations in the gene encoding lamins A/C in autosomal dominant limb girdle muscular dystrophy with atrioventricular conduction disturbances (LGMD1B). Hum Mol Genet. 2000; 9:1453-1459. [PubMed: 10814726]

132. Münter S, Enninga J, Vazquez-Martinez R, Delbarre E, David-Watine B, Nehrbass U, Shorte SL. Actin polymerisation at the cytoplasmic face of eukaryotic nuclei. BMC Cell Biol. 2006; 7:23. [PubMed: 16719903]

133. Naetar N, Korbei B, Kozlov S, Kerenyi MA, Dorner D, Kral R, Gotic I, Fuchs P, Cohen TV, Bittner R, Stewart CL, Foisner R. Loss of nucleoplasmic LAP2alpha-lamin A complexes causes erythroid and epidermal progenitor hyperproliferation. Nat Cell Biol. 2008; 10:1341-1348. [PubMed: 18849980]

134. Nagano A, Koga R, Ogawa M, Kurano Y, Kawada J, Okada R, Hayashi YK, Tsukahara T, Arahata K. Emerin deficiency at the nuclear membrane in patients with Emery-Dreifuss muscular dystrophy. Nat Genet. 1996; 12:254-259. [PubMed: 8589715] 
135. Newport JW, Wilson KL, Dunphy WG. A lamin-independent pathway for nuclear envelope assembly. J Cell Biol. 1990; 111:2247-2259. [PubMed: 2277059]

136. Nikolova V, Leimena C, McMahon AC, Tan JC, Chandar S, Jogia D, Kesteven SH, Michalicek J, Otway R, Verheyen F, Rainer S, Stewart CL, Martin D, Feneley MP, Fatkin D. Defects in nuclear structure and function promote dilated cardiomyopathy in lamin A/C-deficient mice. J Clin Invest. 2004; 113:357-369. [PubMed: 14755333]

137. Novelli G, Muchir A, Sangiuolo F, Helbling-Leclerc A, D’Apice MR, Massart C, Capon F, Sbraccia P, Federici M, Lauro R, Tudisco C, Pallotta R, Scarano G, Dallapiccola B, Merlini L, Bonne G. Mandibuloacral dysplasia is caused by a mutation in LMNA-encoding lamin A/C. Am J Hum Genet. 2002; 71:426-431. [PubMed: 12075506]

138. Olins AL, Herrmann H, Lichter P, Kratzmeier M, Doenecke D, Olins DE. Nuclear envelope and chromatin compositional differences comparing undifferentiated and retinoic acid- and phorbol ester-treated HL-60 cells. Exp Cell Res. 2001; 268:115-127. [PubMed: 11478838]

139. Olins AL, Hoang TV, Zwerger M, Herrmann H, Zentgraf H, Noegel AA, Karakesisoglou I, Hodzic D, Olins DE. The LINC-less granulocyte nucleus. Eur J Cell Biol. 2009; 88:203-214. [PubMed: 19019491]

140. Olins AL, Zwerger M, Herrmann H, Zentgraf H, Simon AJ, Monestier M, Olins DE. The human granulocyte nucleus: Unusual nuclear envelope and heterochromatin composition. Eur J Cell Biol. 2008; 87:279-290. [PubMed: 18396345]

141. Ostlund C, Folker ES, Choi JC, Gomes ER, Gundersen GG, Worman HJ. Dynamics and molecular interactions of linker of nucleoskeleton and cytoskeleton (LINC) complex proteins. J Cell Sci. 2009; 122:4099-4108. [PubMed: 19843581]

142. Ozaki T, Saijo M, Murakami K, Enomoto H, Taya Y, Sakiyama S. Complex formation between lamin A and the retinoblastoma gene product: identification of the domain on lamin A required for its interaction. Oncogene. 1994; 9:2649-2653. [PubMed: 8058329]

143. Padiath QS, Saigoh K, Schiffmann R, Asahara H, Yamada T, Koeppen A, Hogan K, Ptacek LJ, Fu YH. Lamin B1 duplications cause autosomal dominant leukodystrophy. Nat Genet. 2006; 38:1114-1123. [PubMed: 16951681]

144. Padmakumar VC, Abraham S, Braune S, Noegel AA, Tunggal B, Karakesisoglou I, Korenbaum E. Enaptin, a giant actin-binding protein, is an element of the nuclear membrane and the actin cytoskeleton. Exp Cell Res. 2004; 295:330-339. [PubMed: 15093733]

145. Padmakumar VC, Libotte T, Lu W, Zaim H, Abraham S, Noegel AA, Gotzmann J, Foisner R, Karakesisoglou I. The inner nuclear membrane protein Sun1 mediates the anchorage of Nesprin-2 to the nuclear envelope. J Cell Sci. 2005; 118:3419-3430. [PubMed: 16079285]

146. Pajerowski JD, Dahl KN, Zhong FL, Sammak PJ, Discher DE. Physical plasticity of the nucleus in stem cell differentiation. Proc Natl Acad Sci U S A. 2007; 104:15619-15624. [PubMed: 17893336]

147. Paradisi M, McClintock D, Boguslavsky RL, Pedicelli C, Worman HJ, Djabali K. Dermal fibroblasts in Hutchinson-Gilford progeria syndrome with the lamin A G608G mutation have dysmorphic nuclei and are hypersensitive to heat stress. BMC Cell Biol. 2005; 6:27. [PubMed: 15982412]

148. Pare GC, Easlick JL, Mislow JM, McNally EM, Kapiloff MS. Nesprin-1alpha contributes to the targeting of mAKAP to the cardiac myocyte nuclear envelope. Exp Cell Res. 2005; 303:388-399. [PubMed: 15652351]

149. Paszek MJ, Zahir N, Johnson KR, Lakins JN, Rozenberg GI, Gefen A, Reinhart-King CA, Margulies SS, Dembo M, Boettiger D, Hammer DA, Weaver VM. Tensional homeostasis and the malignant phenotype. Cancer Cell. 2005; 8:241-254. [PubMed: 16169468]

150. Pederson T. As functional nuclear actin comes into view, is it globular, filamentous, or both? J Cell Biol. 2008; 180:1061-1064. [PubMed: 18347069]

151. Pederson T, Aebi U. Actin in the nucleus: what form and what for? J Struct Biol. 2002; 140:3-9. [PubMed: 12490148]

152. Pederson T, Aebi U. Nuclear actin extends, with no contraction in sight. Mol Biol Cell. 2005; 16:5055-5060. [PubMed: 16148048] 
153. Percipalle P, Visa N. Molecular functions of nuclear actin in transcription. J Cell Biol. 2006; 172:967-971. [PubMed: 16549500]

154. Philip JT, Dahl KN. Nuclear mechanotransduction: response of the lamina to extracellular stress with implications in aging. J Biomech. 2008; 41:3164-3170. [PubMed: 18945430]

155. Prokocimer M, Margalit A, Gruenbaum Y. The nuclear lamina and its proposed roles in tumorigenesis: projection on the hematologic malignancies and future targeted therapy. J Struct Biol. 2006; 155:351-360. [PubMed: 16697219]

156. Puckelwartz MJ, Kessler E, Zhang Y, Hodzic D, Randles KN, Morris G, Earley JU, Hadhazy M, Holaska JM, Mewborn SK, Pytel P, McNally EM. Disruption of nesprin-1 produces an Emery Dreifuss muscular dystrophy-like phenotype in mice. Hum Mol Genet. 2009; 18:607-620. [PubMed: 19008300]

157. Rosenberg-Hasson Y, Renert-Pasca M, Volk T. A Drosophila dystrophin-related protein, MSP-300, is required for embryonic muscle morphogenesis. Mech Dev. 1996; 60:83-94. [PubMed: 9025063]

158. Roux KJ, Crisp ML, Liu Q, Kim D, Kozlov S, Stewart CL, Burke B. Nesprin 4 is an outer nuclear membrane protein that can induce kinesin-mediated cell polarization. Proc Natl Acad Sci U S A. 2009; 106:2194-2199. [PubMed: 19164528]

159. Rowat A, Foster L, Nielsen M, Weiss M, Ipsen J. Characterization of the elastic properties of the nuclear envelope. J Roy Soc Interface. 2005; 2:63-69. [PubMed: 16849165]

160. Rowat AC, Lammerding J, Herrmann H, Aebi U. Towards an integrated understanding of the structure and mechanics of the cell nucleus. Bioessays. 2008; 30:226-236. [PubMed: 18293361]

161. Rowat AC, Lammerding J, Ipsen JH. Mechanical properties of the cell nucleus and the effect of emerin deficiency. Biophys J. 2006; 91:4649-4664. [PubMed: 16997877]

162. Sakaki M, Koike H, Takahashi N, Sasagawa N, Tomioka S, Arahata K, Ishiura S. Interaction between emerin and nuclear lamins. J Biochem (Tokyo). 2001; 129:321-327. [PubMed: 11173535]

163. Salpingidou G, Smertenko A, Hausmanowa-Petrucewicz I, Hussey PJ, Hutchison CJ. A novel role for the nuclear membrane protein emerin in association of the centrosome to the outer nuclear membrane. J Cell Biol. 2007; 178:897-904. [PubMed: 17785515]

164. Schape J, Prausse S, Radmacher M, Stick R. Influence of lamin A on the mechanical properties of amphibian oocyte nuclei measured by atomic force microscopy. Biophys J. 2009; 96:4319-4325. [PubMed: 19450502]

165. Schirmer EC, Florens L, Guan T, Yates JR 3rd, Gerace L. Nuclear membrane proteins with potential disease links found by subtractive proteomics. Science. 2003; 301:1380-1382. [PubMed: 12958361]

166. Schirmer EC, Gerace L. The stability of the nuclear lamina polymer changes with the composition of lamin subtypes according to their individual binding strengths. J Biol Chem. 2004; 279:42811-42817. [PubMed: 15284226]

167. Schmitt J, Benavente R, Hodzic D, Hoog C, Stewart CL, Alsheimer M. Transmembrane protein Sun2 is involved in tethering mammalian meiotic telomeres to the nuclear envelope. Proc Natl Acad Sci U S A. 2007; 104:7426-7431. [PubMed: 17452644]

168. Schoenenberger CA, Buchmeier S, Boerries M, Sütterlin R, Aebi U, Jockusch BM. Conformation-specific antibodies reveal distinct actin structures in the nucleus and the cytoplasm. J Struct Biol. 2005; 152:157-168. [PubMed: 16297639]

169. Shackleton S, Lloyd DJ, Jackson SN, Evans R, Niermeijer MF, Singh BM, Schmidt H, Brabant G, Kumar S, Durrington PN, Gregory S, O'Rahilly S, Trembath RC. LMNA, encoding lamin $\mathrm{A} / \mathrm{C}$, is mutated in partial lipodystrophy. Nat Genet. 2000; 24:153-156. [PubMed: 10655060]

170. Shimi T, Pfleghaar K, Kojima S, Pack CG, Solovei I, Goldman AE, Adam SA, Shumaker DK, Kinjo M, Cremer T, Goldman RD. The A- and B-type nuclear lamin networks: microdomains involved in chromatin organization and transcription. Genes Dev. 2008; 22:3409-3421. [PubMed: 19141474]

171. Sjakste N, Sjakste T, Vikmanis U. Role of the nuclear matrix proteins in malignant transformation and cancer diagnosis. Exp Oncol. 2004; 26:170-178. [PubMed: 15494683] 
172. Spann TP, Goldman AE, Wang C, Huang S, Goldman RD. Alteration of nuclear lamin organization inhibits RNA polymerase II-dependent transcription. J Cell Biol. 2002; 156:603608. [PubMed: 11854306]

173. Spencer VA, Samuel SK, Davie JR. Altered profiles in nuclear matrix proteins associated with DNA in situ during progression of breast cancer cells. Cancer Res. 2001; 61:1362-1366. [PubMed: 11245435]

174. Starr DA, Han M. Role of ANC-1 in tethering nuclei to the actin cytoskeleton. Science. 2002; 298:406-409. [PubMed: 12169658]

175. Stehbens WE, Delahunt B, Shozawa T, Gilbert-Barness E. Smooth muscle cell depletion and collagen types in progeric arteries. Cardiovasc Pathol. 2001; 10:133-136. [PubMed: 11485857]

176. Stehbens WE, Wakefield SJ, Gilbert-Barness E, Olson RE, Ackerman J. Histological and ultrastructural features of atherosclerosis in progeria. Cardiovasc Pathol. 1999; 8:29-39. [PubMed: 10722246]

177. Stewart C, Burke B. Teratocarcinoma stem cells and early mouse embryos contain only a single major lamin polypeptide closely resembling lamin B. Cell. 1987; 51:383-392. [PubMed: 3311384]

178. Storch KN, Taatjes DJ, Bouffard NA, Locknar S, Bishop NM, Langevin HM. Alpha smooth muscle actin distribution in cytoplasm and nuclear invaginations of connective tissue fibroblasts. Histochem Cell Biol. 2007; 127:523-530. [PubMed: 17310383]

179. Sullivan T, Escalante-Alcalde D, Bhatt H, Anver M, Bhat N, Nagashima K, Stewart CL, Burke B. Loss of A-type lamin expression compromises nuclear envelope integrity leading to muscular dystrophy. J Cell Biol. 1999; 147:913-920. [PubMed: 10579712]

180. Tang CW, Maya-Mendoza A, Martin C, Zeng K, Chen S, Feret D, Wilson SA, Jackson DA. The integrity of a lamin-B1-dependent nucleoskeleton is a fundamental determinant of RNA synthesis in human cells. J Cell Sci. 2008; 121:1014-1024. [PubMed: 18334554]

181. Theret DP, Levesque MJ, Sato M, Nerem RM, Wheeler LT. The application of a homogeneous half-space model in the analysis of endothelial cell micropipette measurements. J Biomech Eng. 1988; 110:190-199. [PubMed: 3172738]

182. Thomas CH, Collier JH, Sfeir CS, Healy KE. Engineering gene expression and protein synthesis by modulation of nuclear shape. Proc Natl Acad Sci U S A. 2002; 99:1972-1977. [PubMed: 11842191]

183. Thoumine O, Ott A. Time scale dependent viscoelastic and contractile regimes in fibroblasts probed by microplate manipulation. J Cell Sci. 1997; 110 ( Pt 17):2109-2116. [PubMed: 9378761]

184. Towbin BD, Meister P, Gasser SM. The nuclear envelope--a scaffold for silencing? Curr Opin Genet Dev. 2009; 19:180-186. [PubMed: 19303765]

185. Tseng Y, Lee JS, Kole TP, Jiang I, Wirtz D. Micro-organization and visco-elasticity of the interphase nucleus revealed by particle nanotracking. J Cell Sci. 2004; 117:2159-2167. [PubMed: 15090601]

186. Vantyghem MC, Pigny P, Maurage CA, Rouaix-Emery N, Stojkovic T, Cuisset JM, Millaire A, Lascols O, Vermersch P, Wemeau JL, Capeau J, Vigouroux C. Patients with familial partial lipodystrophy of the Dunnigan type due to a LMNA R482W mutation show muscular and cardiac abnormalities. J Clin Endocrinol Metab. 2004; 89:5337-5346. [PubMed: 15531479]

187. Varela I, Cadinanos J, Pendas AM, Gutierrez-Fernandez A, Folgueras AR, Sanchez LM, Zhou Z, Rodriguez FJ, Stewart CL, Vega JA, Tryggvason K, Freije JM, Lopez-Otin C. Accelerated ageing in mice deficient in Zmpste24 protease is linked to p53 signalling activation. Nature. 2005; 437:564-568. [PubMed: 16079796]

188. Vaziri A, Mofrad MR. Mechanics and deformation of the nucleus in micropipette aspiration experiment. J Biomech. 2007; 40:2053-2062. [PubMed: 17112531]

189. Venables RS, McLean S, Luny D, Moteleb E, Morley S, Quinlan RA, Lane EB, Hutchison CJ. Expression of individual lamins in basal cell carcinomas of the skin. Br J Cancer. 2001; 84:512519. [PubMed: 11207047] 
190. Vergnes L, Peterfy M, Bergo MO, Young SG, Reue K. Lamin B1 is required for mouse development and nuclear integrity. Proc Natl Acad Sci U S A. 2004; 101:10428-10433. [PubMed: 15232008]

191. Verstraeten VL, Lammerding J. Experimental techniques for study of chromatin mechanics in intact nuclei and living cells. Chromosome Res. 2008; 16:499-510. [PubMed: 18461486]

192. Vigouroux C, Auclair M, Dubosclard E, Pouchelet M, Capeau J, Courvalin JC, Buendia B. Nuclear envelope disorganization in fibroblasts from lipodystrophic patients with heterozygous R482Q/W mutations in the lamin A/C gene. J Cell Sci. 2001; 114:4459-4468. [PubMed: 11792811]

193. Warren DT, Zhang Q, Weissberg PL, Shanahan CM. Nesprins: intracellular scaffolds that maintain cell architecture and coordinate cell function? Expert Rev Mol Med. 2005; 7:1-15. [PubMed: 15953398]

194. Wiche G. Role of plectin in cytoskeleton organization and dynamics. J Cell Sci. 1998; 111 (Pt 17):2477-2486. [PubMed: 9701547]

195. Wiesel N, Mattout A, Melcer S, Melamed-Book N, Herrmann H, Medalia O, Aebi U, Gruenbaum Y. Laminopathic mutations interfere with the assembly, localization, and dynamics of nuclear lamins. Proc Natl Acad Sci U S A. 2008; 105:180-185. [PubMed: 18162544]

196. Wilhelmsen K, Litjens SH, Kuikman I, Tshimbalanga N, Janssen H, van den Bout I, Raymond K, Sonnenberg A. Nesprin-3, a novel outer nuclear membrane protein, associates with the cytoskeletal linker protein plectin. J Cell Biol. 2005; 171:799-810. [PubMed: 16330710]

197. Wilkinson FL, Holaska JM, Zhang Z, Sharma A, Manilal S, Holt I, Stamm S, Wilson KL, Morris GE. Emerin interacts in vitro with the splicing-associated factor, YT521-B. Eur J Biochem. 2003; 270:2459-2466. [PubMed: 12755701]

198. Willis ND, Cox TR, Rahman-Casans SF, Smits K, Przyborski SA, van den Brandt P, van Engeland M, Weijenberg M, Wilson RG, de Bruine A, Hutchison CJ. Lamin A/C is a risk biomarker in colorectal cancer. PLoS ONE. 2008; 3:e2988. [PubMed: 18714339]

199. Wilson KL, Holaska JM, de Oca RM, Tifft K, Zastrow M, Segura-Totten M, Mansharamani M, Bengtsson L. Nuclear membrane protein emerin: roles in gene regulation, actin dynamics and human disease. Novartis Found Symp. 2005; 264:51-58. discussion 58-62, 227-230. [PubMed: 15773747]

200. Wolf K, Friedl P. Molecular mechanisms of cancer cell invasion and plasticity. Br J Dermatol. 2006; 154:11-15. [PubMed: 16712711]

201. Wolf K, Wu YI, Liu Y, Geiger J, Tam E, Overall C, Stack MS, Friedl P. Multi-step pericellular proteolysis controls the transition from individual to collective cancer cell invasion. Nat Cell Biol. 2007; 9:893-904. [PubMed: 17618273]

202. Worman HJ, Fong LG, Muchir A, Young SG. Laminopathies and the long strange trip from basic cell biology to therapy. J Clin Invest. 2009; 119:1825-1836. [PubMed: 19587457]

203. Worman HJ, Gundersen GG. Here come the SUNs: a nucleocytoskeletal missing link. Trends Cell Biol. 2006; 16:67-69. [PubMed: 16406617]

204. Xiong H, Rivero F, Euteneuer U, Mondal S, Mana-Capelli S, Larochelle D, Vogel A, Gassen B, Noegel AA. Dictyostelium Sun-1 connects the centrosome to chromatin and ensures genome stability. Traffic. 2008; 9:708-724. [PubMed: 18266910]

205. Yabuki M, Miyake T, Doi Y, Fujiwara T, Hamazaki K, Yoshioka T, Horton AA, Utsumi K. Role of nuclear lamins in nuclear segmentation of human neutrophils. Physiol Chem Phys Med NMR. 1999; 31:77-84. [PubMed: 10816760]

206. Young KG, Kothary R. Spectrin repeat proteins in the nucleus. Bioessays. 2005; 27:144-152. [PubMed: 15666356]

207. Zastrow MS, Flaherty DB, Benian GM, Wilson KL. Nuclear titin interacts with A- and B-type lamins in vitro and in vivo. J Cell Sci. 2006; 119:239-249. [PubMed: 16410549]

208. Zastrow MS, Vlcek S, Wilson KL. Proteins that bind A-type lamins: integrating isolated clues. J Cell Sci. 2004; 117:979-987. [PubMed: 14996929]

209. Zhang J, Felder A, Liu Y, Guo LT, Lange S, Dalton ND, Gu Y, Peterson KL, Mizisin AP, Shelton GD, Lieber RL, Chen J. Nesprin 1 is critical for nuclear positioning and anchorage. Hum Mol Genet. 2010; 19:329-341. [PubMed: 19864491] 
210. Zhang Q, Bethmann C, Worth NF, Davies JD, Wasner C, Feuer A, Ragnauth CD, Yi Q, Mellad JA, Warren DT, Wheeler MA, Ellis JA, Skepper JN, Vorgerd M, Schlotter-Weigel B, Weissberg PL, Roberts RG, Wehnert M, Shanahan CM. Nesprin-1 and -2 are involved in the pathogenesis of Emery Dreifuss muscular dystrophy and are critical for nuclear envelope integrity. Hum Mol Genet. 2007; 16:2816-2833. [PubMed: 17761684]

211. Zhang Q, Ragnauth CD, Skepper JN, Worth NF, Warren DT, Roberts RG, Weissberg PL, Ellis JA, Shanahan CM. Nesprin-2 is a multi-isomeric protein that binds lamin and emerin at the nuclear envelope and forms a subcellular network in skeletal muscle. J Cell Sci. 2005; 118:673687. [PubMed: 15671068]

212. Zhang Q, Skepper JN, Yang F, Davies JD, Hegyi L, Roberts RG, Weissberg PL, Ellis JA, Shanahan CM. Nesprins: a novel family of spectrin-repeat-containing proteins that localize to the nuclear membrane in multiple tissues. J Cell Sci. 2001; 114:4485-4498. [PubMed: 11792814]

213. Zhang X, Lei K, Yuan X, Wu X, Zhuang Y, Xu T, Xu R, Han M. SUN1/2 and Syne/Nesprin-1/2 complexes connect centrosome to the nucleus during neurogenesis and neuronal migration in mice. Neuron. 2009; 64:173-187. [PubMed: 19874786]

214. Zhen YY, Libotte T, Munck M, Noegel AA, Korenbaum E. NUANCE, a giant protein connecting the nucleus and actin cytoskeleton. J Cell Sci. 2002; 115:3207-3222. [PubMed: 12118075]

215. Zink D, Fischer AH, Nickerson JA. Nuclear structure in cancer cells. Nat Rev Cancer. 2004; 4:677-687. [PubMed: 15343274] 


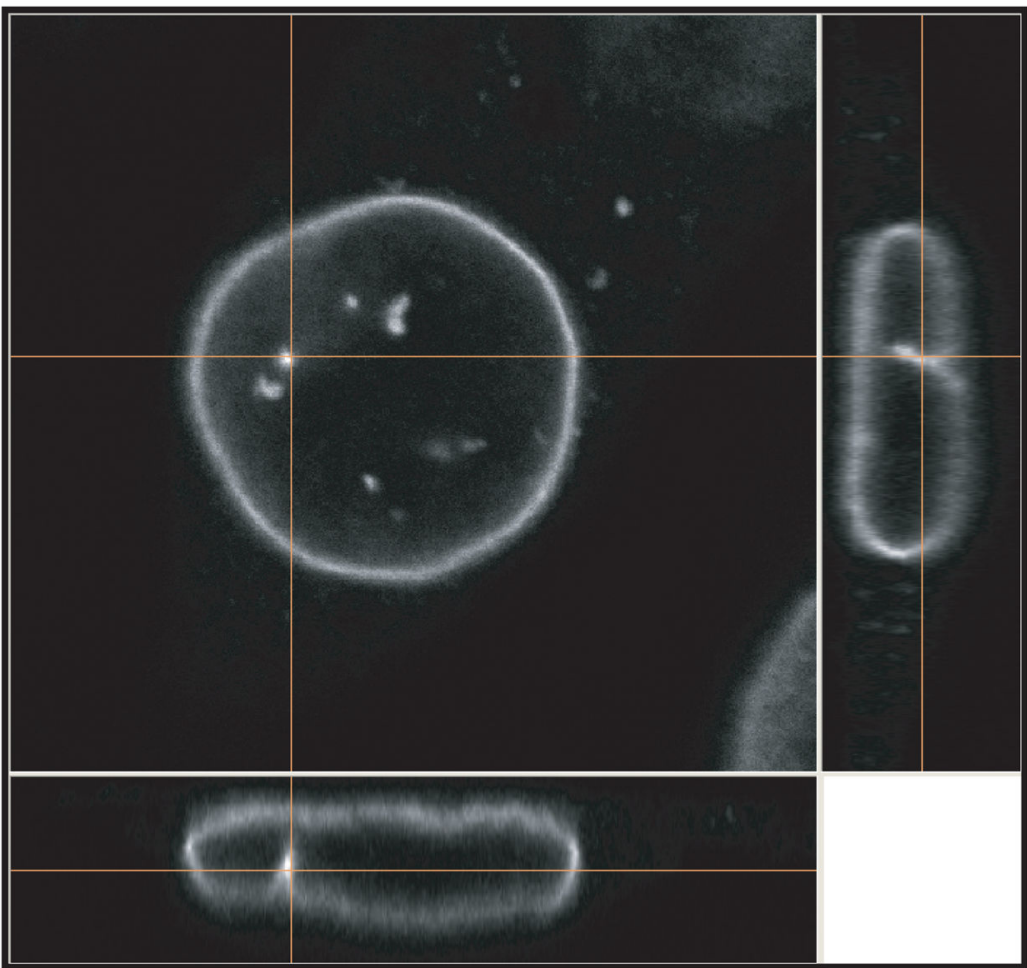

Figure 1.

Orthoview of mouse embryo fibroblast immunofluorescently labeled for lamin B1 and imaged with an Nikon A1 confocal microscope. The micrograp shows the disk-shaped nuclear morphology in the adherent fibroblast cultured on a fibronectin coated cover slip. 


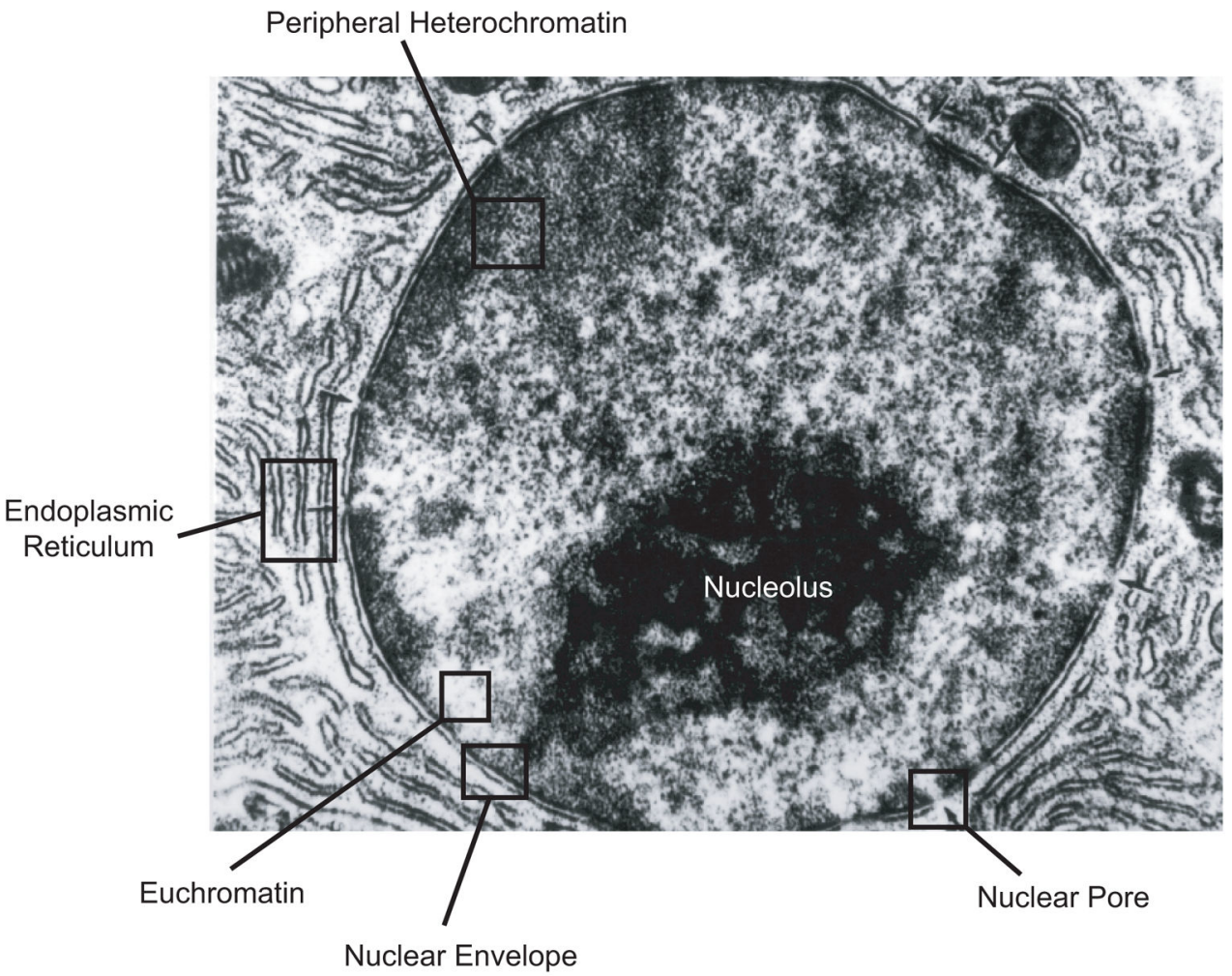

Figure 2.

Transmission electon micrograph of a hepatocyte nucleus showing the major structural elements of the nucleus. Adapted from NUS Histonet, WWW Electronic Guide to Histology for Medicine and Dentistry, online at http://www.med.nus.edu.sg/ant/histonet/txt/tacsem/ tac01.sem.html. TEM image courtesy of Dr. P. Gopalakrishnakone. 


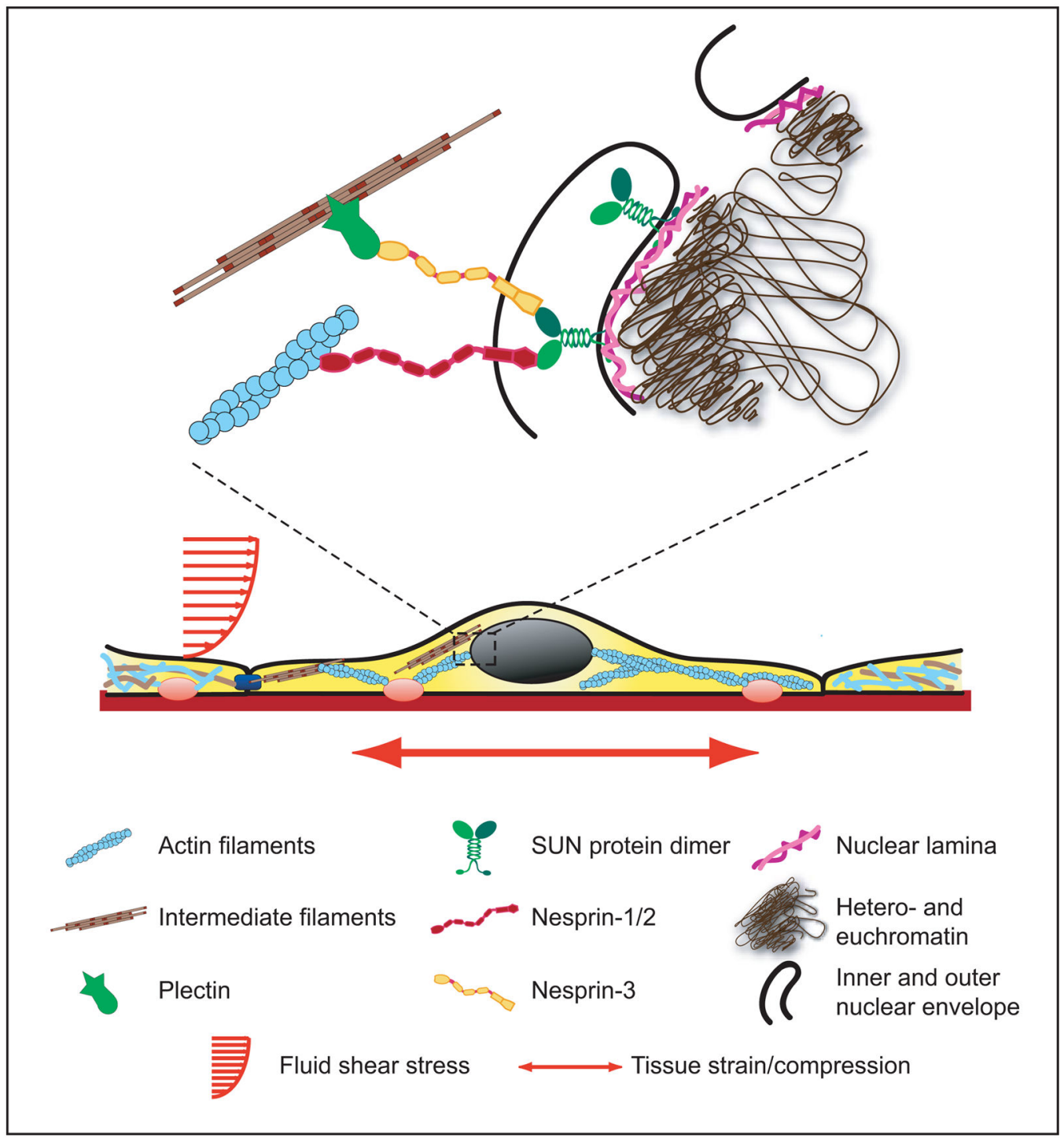

Figure 3.

Schematic overview of nuclear structure and nuclear cytoskeletal coupling. (Figure taken from Dahl KN, Ribeiro AJS, and Lammerding J, Circ Res 2008 (102): 13071318). 

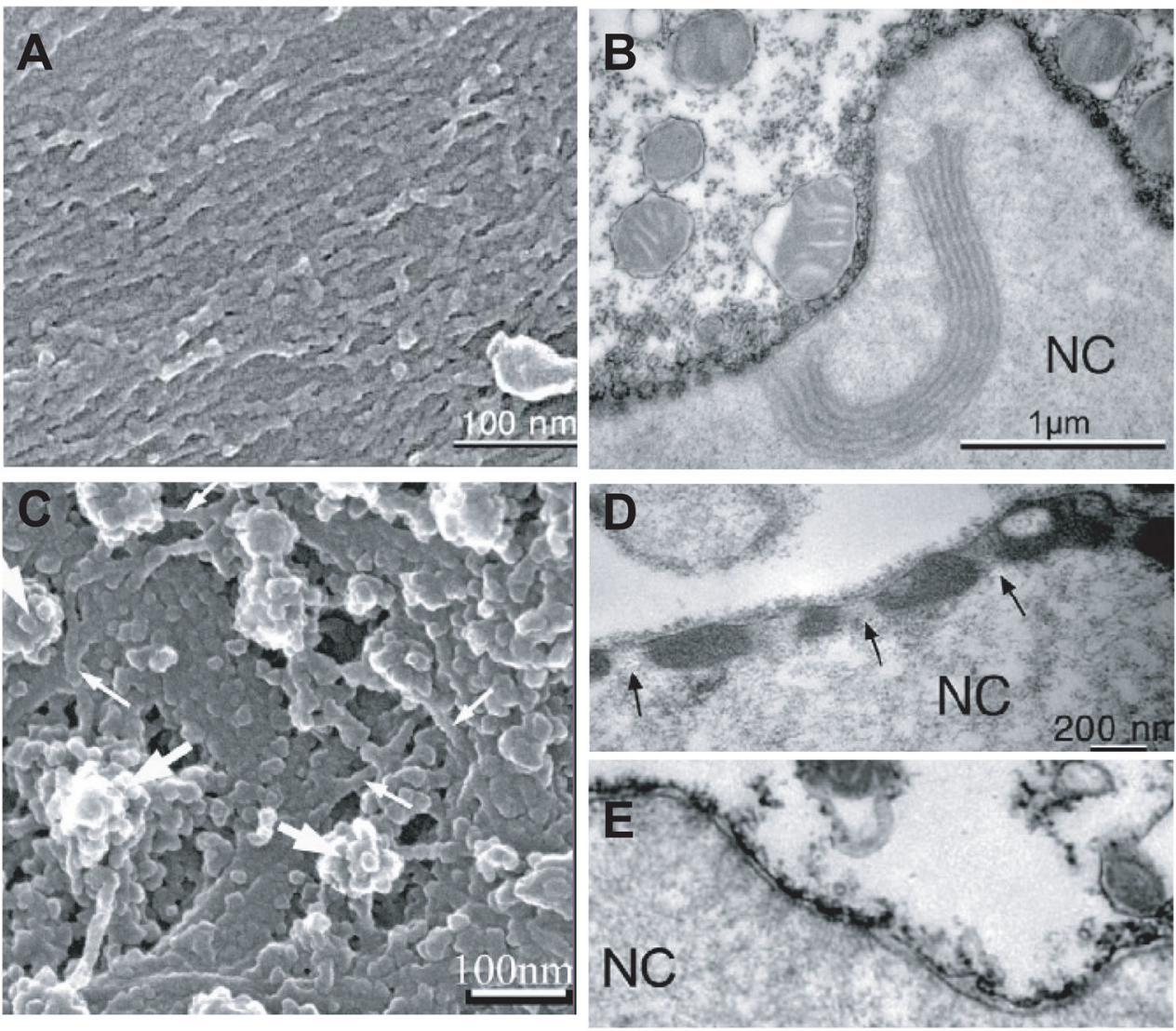

Figure 4.

Comparison of A-type and B-type lamins ectopically expressed in Xenopus oocyte nuclei. (A) Scanning electon micrograph of membrane arrays covered by lamin B2 filaments. (B) Transmission electon micrograph (TEM) section of an isolated oocyte nucleus expressing lamin B2. (C) Lamin A filaments. Filaments that are arranged in layered bundles are indicated by small arrows; they surround nuclear pore baskets (large arrrows). (D, E) TEM section of oocyte expressing lamin A (D) and control (E). The lamina is hardly visible in the control nuclei (E) but forms a thick electron-dense layer in oocytes expressing lamin A (D), which leaves the nuclear pores clear (arrows).

(Figure assembled from panels taken from Goldberg et al. J Cell Sci 2007 (121): 215-221). 

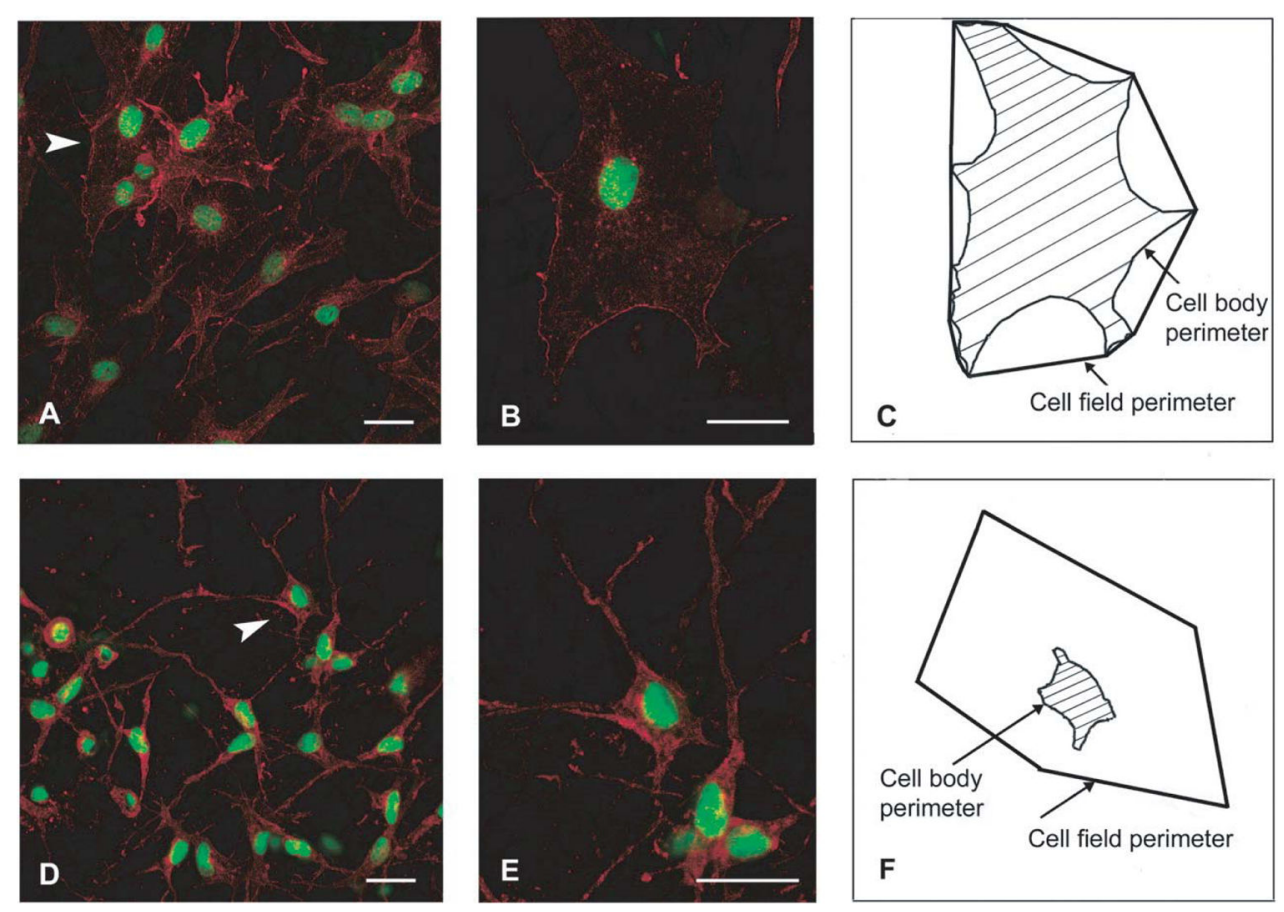

Figure 5.

Changes in fibroblast morphology in response to strain. Mouse subcutaneous tissue was stretched ex vivo (A, B) or maintained without stretch (D, E), subsequently fixed and stained with phalloidin (red) and SYTOX (green), and imaged by confocal microscopy. Panels (A) and (D) are composite projections of image stacks containing 20 optical sections taken at 1$\mu \mathrm{m}$ intervals. Panels (B) and (E) are projections of relevant optical sections containing the cells indicated by arrowheads in (A) and (D), respectively. Scale bars, $40 \mu \mathrm{m}$. (C) and (F): Outlines of the cell bodies in (B) and (E).

(Figure taken from Langevin at al. Am J Physiol Cell Physiol (2005). 288: C747-C756). 


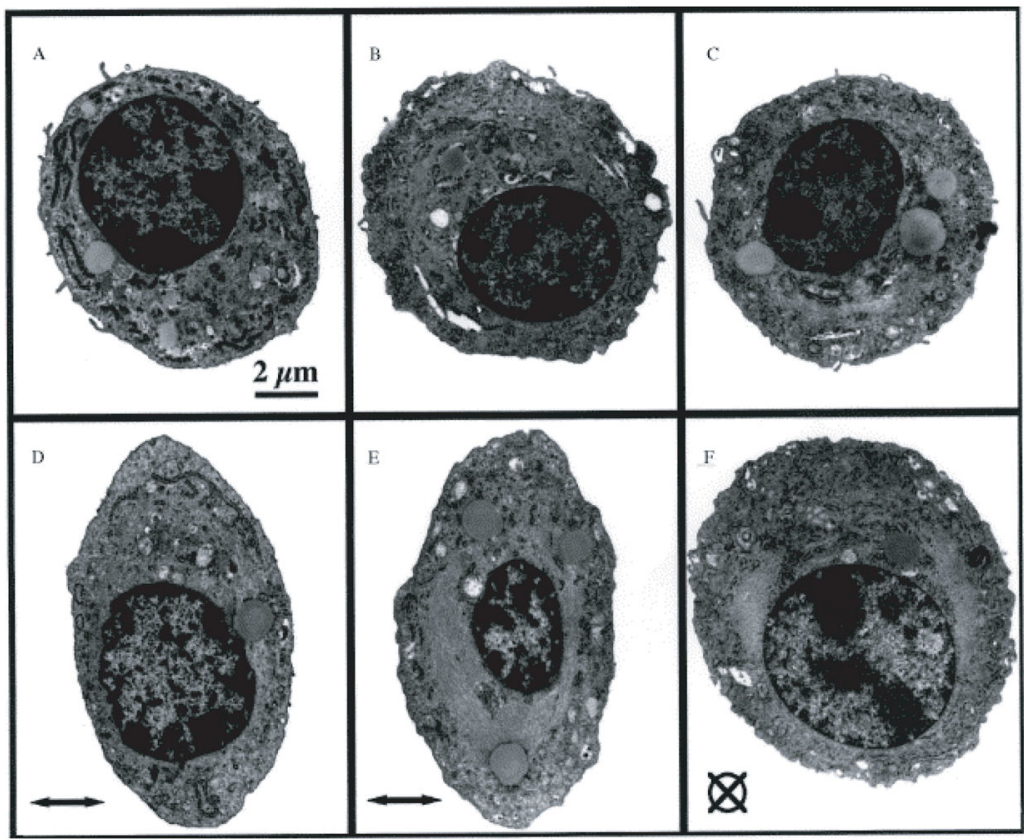

Figure 6.

Transmission electron micrographs of condrocytes embedded in agarose constructs held unstrained (A-C) or subjected to $20 \%$ compression (D-F). All micrographs were taken at the same magnification (Scale bar=2 $\mu \mathrm{m}$ ). The direction of the applied strain is indicated by the horizontal arrow in (D) and (E) and a crossed circle in (F).

(Figure taken from Lee at al. J Biomechanics. 2000. 33: 81-85). 
A
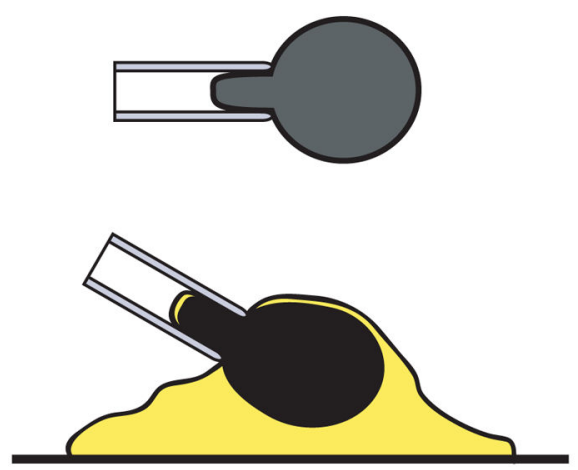

B

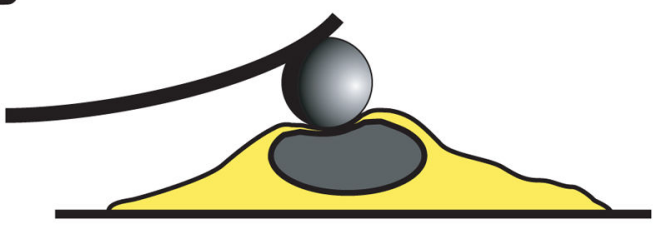

C
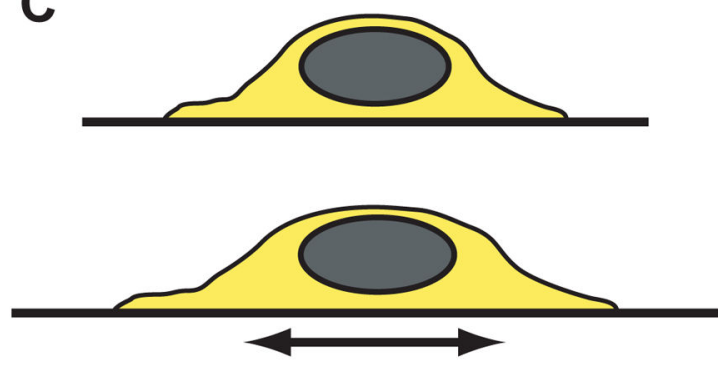

D

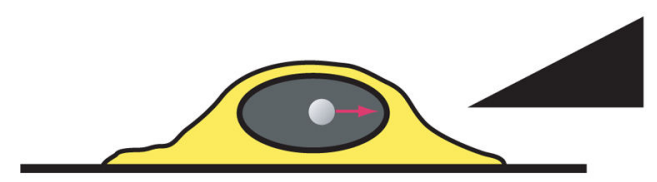

E

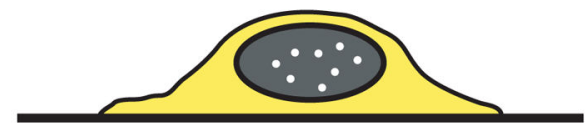

Figure 7.

Overview of experimental techniques to probe nuclear mechanics. (A) Micropipette aspiration on isolated nuclei (top) or in intact cells after cytoskeletal disruption (bottom). (B) Atomic force microscopy. (C) Substrate strain. (D) Active microrheology. (E). Passive microrheology. 

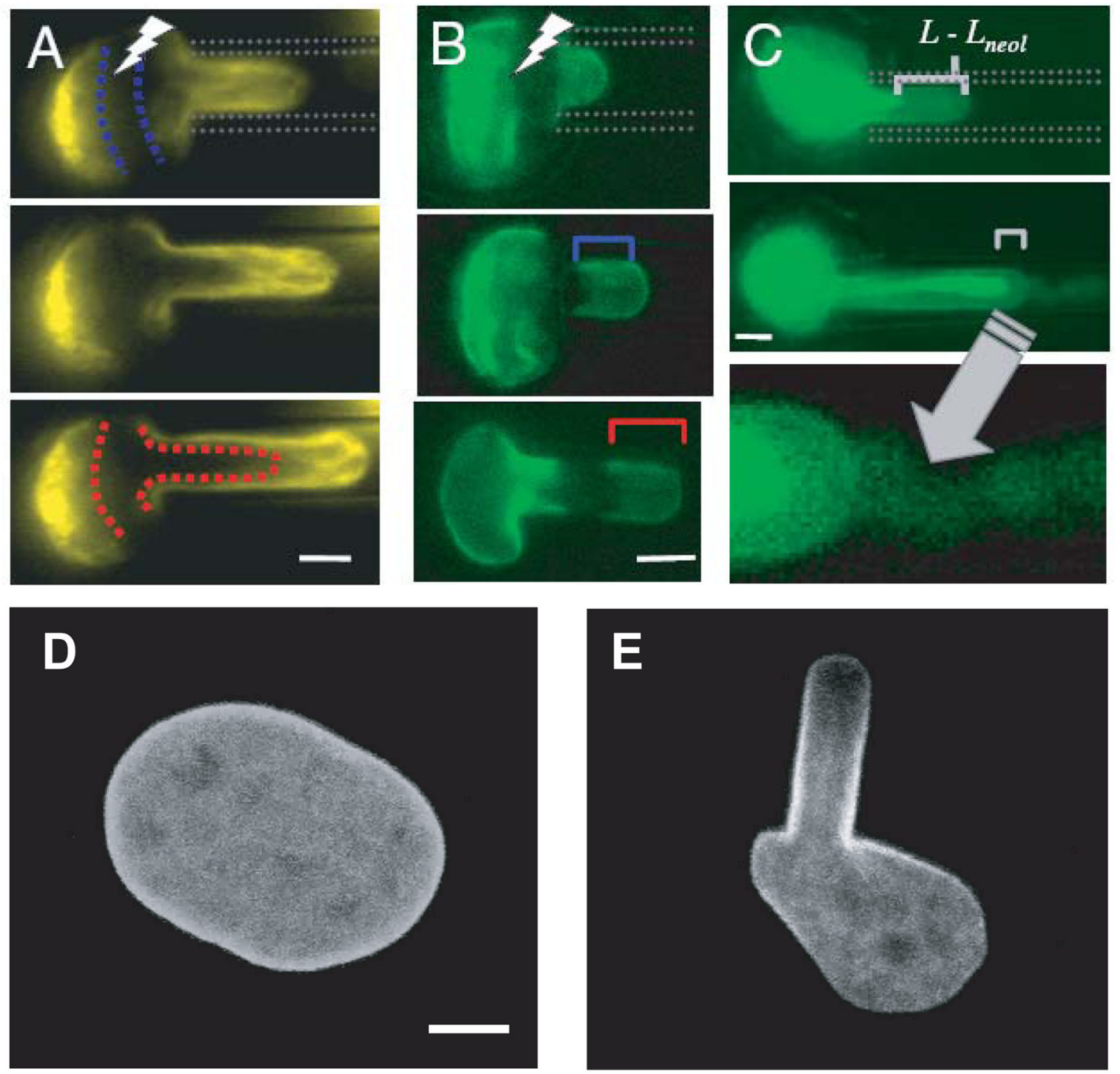

Figure 8.

Distinct differences in the deformation of the elastic laminar and the viscoelastic nuclear interior during micropipette aspiration. (A) Tracking a bleached reagion within GFP-H2B labeled chromatin reveals chromatin flow within the pipette. (B) Deformation of the GFPlamin A labeled lamina stretched into the micropipette, showing elastic stretch of the lamina (C) Nucleoli slowly follow chromatin toward the nuclear tip. Scale bar for (A-C): $3 \mu \mathrm{m}$. (D, E). Fibroblast with nuclear lamina labeled by GFP-lamin A before (D) and during (E) micropipette aspiration. The fluorescence gradient suggests thinning of the elastic nuclear lamina towards the tip.

(Panels (A-C) taken from Pajerowski et al. Proc Nat Acad Sci 2007. 104: 15619-15624

Panels (D, E) taken from Rowat, Lammerding and Ipsen Biophys J 2006. 91: 4649-4664) 


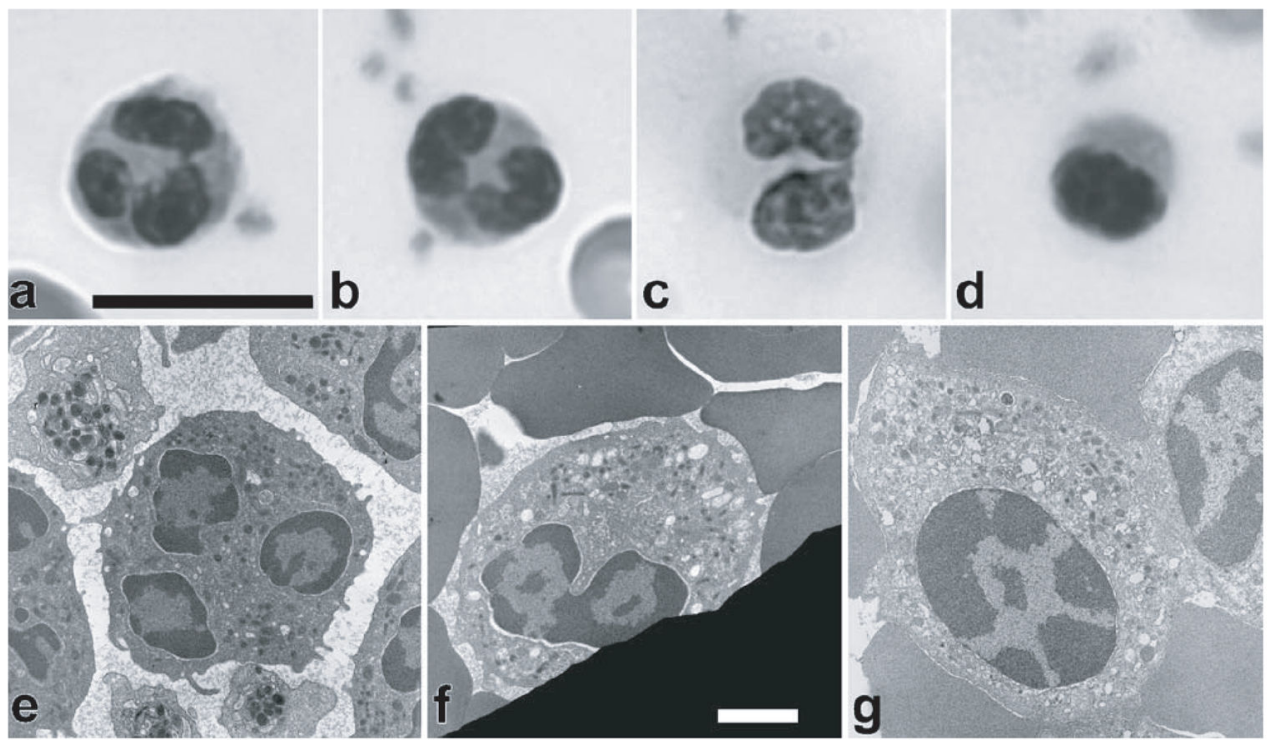

Figure 9.

Defects in nuclear morphology in neutrophils from blood smears of individuals with PelgerHuet anomaly (PHA) labeled with Wright-Giemsa stain. (A) Normal neutrophil with lobulated nucleus. (B) Heterozygous PHA neutrophil with a bilobed nucleus, taken from the mother of the homozygous individual. (C) Heterozygous PHA neutrophil with a bilobed nucleus, taken from the father of the homozygote. (D) Homozygous PHA neutrophil showing an ovoid nucleus with chromatin clumping. Scale bar for light micrographs: $10 \mu \mathrm{m}$. (E-G) Transmission electron micrographs of normal human neutrophil nucleus with three apparent lobes and extensive peripheral heterochromatin (E), heterozygous PHA neutrophil with a bilobed nucleus taken from the father of the homozygote $(\mathrm{F})$, and ovoid nucleus from a homozygous PHA granulocyte exhibiting extensive heterochromatin redistribution $(\mathrm{G})$. Scale bar for electron micrographs: $1 \mu \mathrm{m}$ (Figure taken from Hoffmann et al. Chromosoma. 2007. 116: 227-235) 

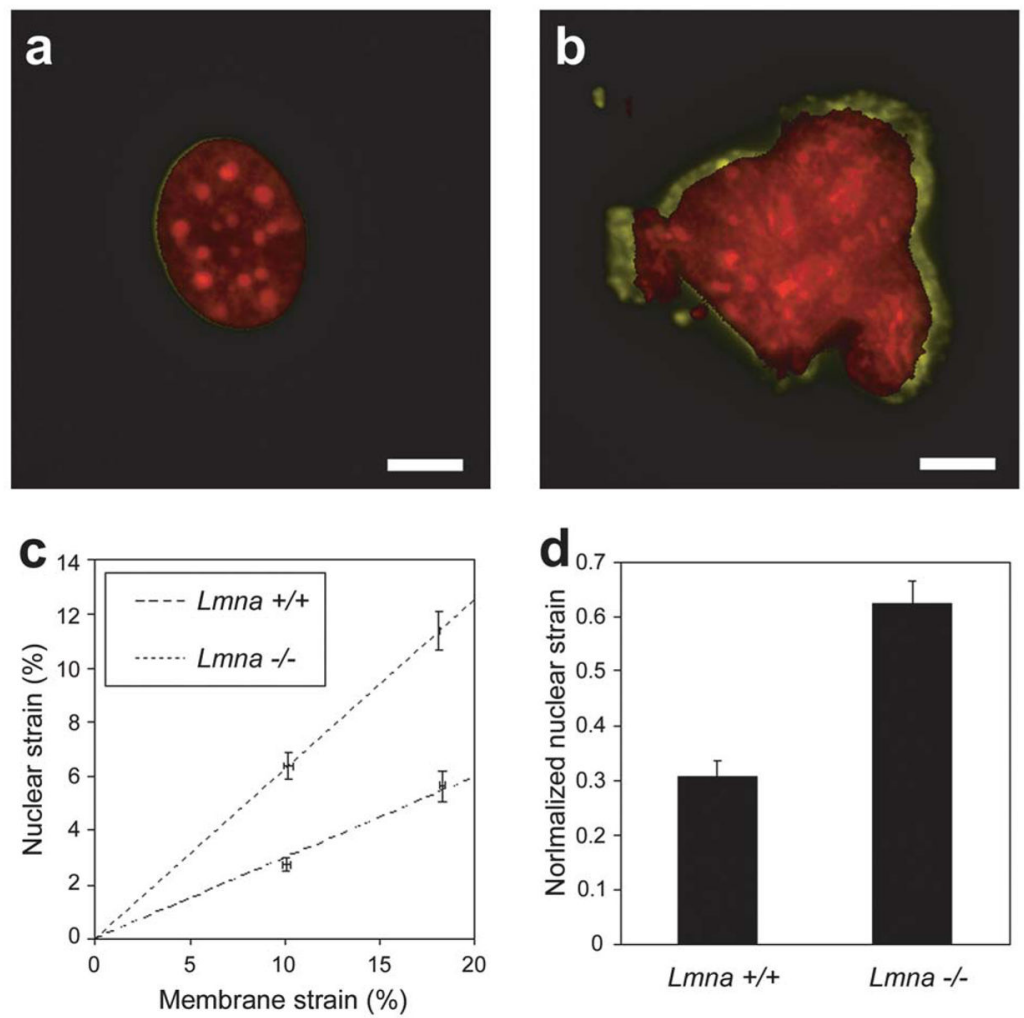

Figure 10.

Abnormasl nuclear mechanics in lamin A/C-deficient fibroblasts. (A) Nucleus of wild-type $(\mathrm{Lmna}+/+)$ fibroblast before strain (red) and during application of $22 \%$ substrate strain (yellow), revealing only minimal nuclear deformation. (B) Lamin A/C-deficient (Lmna-/-) nucleus before strain (red) and during 19\% substrate strain (yellow). Scale bars: $10 \mu \mathrm{m}$. (C) Nuclear strain as a function increases linearly with applied membrane strain, but is significantly larger in Lmna-/- fibroblasts. Dashed lines represent linear regression of the data for each cell type. (D) Maximal normalized nuclear strain (i.e., nuclear strain devided by the applied membrane strain) is significantly increased in Lmna-/- fibroblasts, indicating decreased nuclear stiffness.

(Figure taken from Lammerding et al. J Clin Invest. 2004. 113: 370-378.) 